\title{
Long-period ground motion
} simulation using centroid moment tensor inversion solutions based on the regional three-dimensional model in the Kanto region, Japan

\author{
Shunsuke Takemura ${ }^{{ }^{*}} \mathbb{0}$, Kazuo Yoshimoto ${ }^{2}$ and Katsuhiko Shiomi ${ }^{3}$
}

\begin{abstract}
We conducted centroid moment tensor (CMT) inversions of moderate (Mw 4.5-6.5) earthquakes in the Kanto region, Japan, using a local three-dimensional (3D) model. We then investigated the effects of our 3D CMT solutions on longperiod ground motion simulations. Grid search CMT inversions were conducted using displacement seismograms for periods of 25-100 s. By comparing our 3D CMT solutions with those from the local one-dimensional (1D) catalog, we found that our 3D CMT inversion systematically provides magnitudes smaller than those in the 1D catalog. The Mw differences between 3D and 1D catalogs tend to be significant for earthquakes within the oceanic slab. By comparing ground motion simulations between 1D and 3D velocity models, we confirmed that observed $M w$ differences could be explained by differences in the rigidity structures around the source regions between 3D and 1D velocity models. The 3D velocity structures (especially oceanic crust and mantle) are important for estimating seismic moments in intraslab earthquakes, which are related to fault size estimation. A detailed discussion for intraslab seismicity can be conducted using the 3D CMT catalog. The seismic moments also directly affect the amplitudes of ground motions. The 3D CMT catalog allows us to directly conduct the precise forward and inverse modeling of long-period ground motion without adjusting source models, which have been typically applied in the cases using the 1D CMT catalog. We also conducted long-period ground motion simulations using our 3D CMT solutions to evaluate the reproducibility of long-period ground motions at stations within the Kanto Basin. The simulations of our 3D CMT solutions well-reproduced observed ground motions for periods longer than $10 \mathrm{~s}$, even at stations within the Kanto Basin. The reproducibility of simulations was improved from those using solutions in the 1D catalog.
\end{abstract}

Keywords: CMT inversion, Kanto region, Long-period ground motion, 3D numerical simulation

\section{Introduction}

Long-period ground motions with predominant periods of 3-20 s have often been observed in large sedimentary basins and offshore regions. The duration and amplitude

\footnotetext{
*Correspondence: shunsuke@eri.u-tokyo.ac.jp

'Earthquake Research Institute, The University of Tokyo, 1-1-1 Yayoi,

Bunkyo-ku, Tokyo 113-0032, Japan

Full list of author information is available at the end of the article
}

of long-period ground motion is enhanced due to thick low-velocity sediments along the propagation path (e.g., Boore 1999; Furumura et al. 2001, 2008; Olsen et al. 2006; Day et al. 2008; Gomberg 2018; Kaneko et al. 2019; Takemura et al. 2019a). Thus, long-period ground motions can cause severe resonance and damage of large-scale man-made structures in the densely populated areas. The characteristics of long-period ground motions have been summarized in Koketsu and Miyake (2008). In the

\section{Springer Open}

(c) The Author(s) 2021. This article is licensed under a Creative Commons Attribution 4.0 International License, which permits use, sharing, adaptation, distribution and reproduction in any medium or format, as long as you give appropriate credit to the original author(s) and the source, provide a link to the Creative Commons licence, and indicate if changes were made. The images or other third party material in this article are included in the article's Creative Commons licence, unless indicated otherwise in a credit line to the material. If material is not included in the article's Creative Commons licence and your intended use is not permitted by statutory regulation or exceeds the permitted use, you will need to obtain permission directly from the copyright holder. To view a copy of this licence, visit http://creativeco mmons.org/licenses/by/4.0/. 
Kanto region, Japan, long-period ground motions with predominant periods of 5-10 s have frequently been observed during shallow moderate-to-large earthquakes (e.g., Kinoshita et al. 1992; Miyake and Koketsu 2005; Yoshimoto and Takemura 2014). The propagation feature of long-period ground motion is complicated due to the lateral variations of sedimentary structures within the Kanto Basin (e.g., Koketsu and Kikuchi 2000; Furumura and Hayakawa 2007; Mukai et al. 2018). Long-period ground motion and the structural properties within the Kanto Basin have been studied extensively using observed seismograms and geological surveys to contribute to disaster mitigation in the Tokyo metropolitan area (e.g., Koketsu et al. 2009; Takemura et al. 2015).

Recent advances in numerical simulation codes (e.g., Gokhberg and Fichtner 2016; Maeda et al. 2017) and local/regional three-dimensional (3D) velocity structure models (e.g., Koketsu et al. 2012; Kennett et al. 2013; Stephenson et al. 2017) have enabled the implementation of realistic 3D simulations of long-period ground motion (e.g., Komatitsch 2004; Iwaki et al. 2018; Wirth et al. 2019; Takemura et al. 2019a), and the estimation of structural properties (e.g., Tape et al. 2009; Gao and Shen 2014; Miyoshi et al. 2017). In forward and inverse modeling of long-period ground motion and structural properties along propagation paths, an assumption of a double-couple point source is usually assumed. The centroid moment tensor (CMT) solutions based on displacement for periods longer than $20 \mathrm{~s}$ are generally considered robust against structural heterogeneities, compared to first-motion solutions (e.g., Takemura et al. 2016). As such, one-dimensional (1D) velocity models are adopted in local/global CMT inversion systems (e.g., Kubo et al. 2002; Bernardi et al. 2004; Vallée et al. 2011; Ekström et al. 2012); these solutions are typically used in ground motion simulations. However, in regions with strong heterogeneities, such as thick sediments and subducting oceanic plates, focal mechanisms could be incorrectly estimated using conventional CMT methods with a $1 \mathrm{D}$ velocity model. To address this issue, the CMT inversion based on Green's functions using the local/regional 3D model has been developed in such regions (e.g., Lee et al. 2013; Hejrani et al. 2017; Okamoto et al. 2018; Takemura et al. 2018a, 2018b, b, 2020; Wang and Zhan 2020; Hejrani and Tkalčić 2020). By using the 3D CMT results of moderate earthquakes along the Nankai Trough, Takemura et al. (2020) demonstrated that the differences in centroid depths and focal mechanisms between 1D and their 3D CMT solutions were significant for offshore earthquakes due to offshore heterogeneities. These differences could affect ground motion simulations (e.g., Takemura et al. 2019c). To achieve precise forward and inverse modeling of long-period ground motions in the Kanto region, where large sedimentary basin and two subducting plates exist, accurate CMT solutions is required.

In this study, we conduct CMT inversions of moderate earthquakes in the Kanto region based on the Green's function calculated using the local 3D model. We evaluate differences in source parameters between CMT solutions obtained from 1D and 3D earth model. We conduct ground motion simulations using 3D CMT solutions to discuss the effects of CMT solutions on longperiod ground motion modeling in the Kanto Basin. To accurately model phases and amplitudes of long-period ground motion, we demonstrate that the adjusted source model should be incorporated in the used 3D model.

\section{Method}

In this study, we used the F-net broadband seismograms of the target earthquakes. At each F-net station (filled triangles in Fig. 1), a broadband velocity seismometer (STS-1, STS-2, or STS-2.5) was installed. The health of sensors has been systematically monitored by the National Research Institute for Earth Science and Disaster Resilience (NIED; Okada et al. 2004; Kimura et al. 2015; National Research Institute for Earth Science and Disaster Resilience 2019). Our target earthquakes were shallow ( $\leq 50 \mathrm{~km}$ ) earthquakes with moment magnitudes $(M w)$ between 4.5 and 6.5, listed in the F-net moment tensor (MT) catalog. The F-net $1 \mathrm{D}$ velocity structure model has been used in the F-net MT catalog (Fukuyama et al. 1998; Kubo et al. 2002). Target earthquakes (focal mechanisms in Fig. 1) occurred within the area of assumed source grids (crosses in Fig. 2a) between April 2017 and March 2020. The data of the Metropolitan Seismic Observation Network (MeSO-net) were also available from the NIED website in the analyzed period (e.g., Kasahara et al. 2009; Sakai and Hirata 2009). As MeSOnet stations were densely deployed around the Tokyo metropolitan area in Japan (inverse triangles in Fig. 1), we also evaluated long-period ground motion in the Kanto Basin using earthquakes that occurred after April 2017.

CMT inversions were conducted using displacement seismograms for periods of 25-100 s. By using the Opensource Seismic Wave Propagation Code software "OpenSWPC" (Maeda et al. 2017), we numerically evaluated Green's functions in the 3D model. We used the Japan Integrated Velocity Structure Model version 1 (JIVSM; Koketsu et al. 2012) as the 3D velocity structure model for this study. The JIVSM was constructed by combine use of geological and geophysical surveys around Japan. The structures beneath the bedrock were modeled using regional-scale tomography and gravity data (e.g., Ryoki 1999; Matsubara et al. 2008; Matsubara and Obara 2011). Detailed procedure for model construction was described in Koketsu et al. (2009, 2012). The JIVSM has 


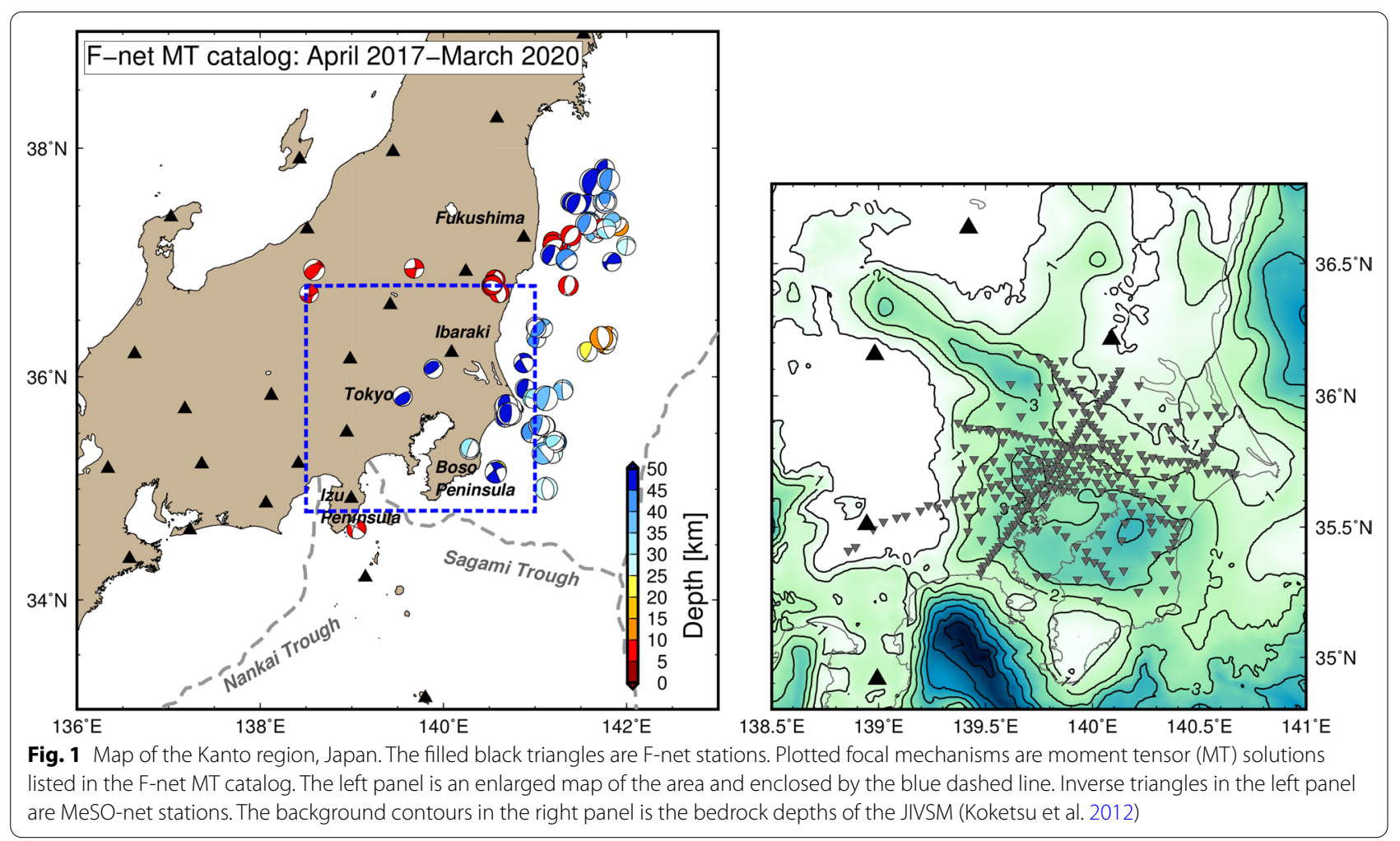

been widely used in the evaluation of ground motion, crustal deformation, and seismic monitoring across Japan (e.g., Guo et al. 2016; Miyazawa 2016; Agata 2020; Oba et al. 2020; Baba et al. 2020). The simulation model covered an area of $600 \times 600 \times 160 \mathrm{~km}^{3}$ (blue dashed rectangle in Fig. 2a), which was discretized by grid intervals of $0.5 \mathrm{~km}$ in the horizontal direction and $0.2 \mathrm{~km}$ in the vertical direction. The physical parameters of each layer in the JIVSM are listed in Table 1 . The minimum $S$-wave velocity in the solid column was assumed to be $1.5 \mathrm{~km} / \mathrm{s}$ for the calculation of 3D Green's functions. Source grids were uniformly distributed at a horizontal interval of $0.1^{\circ}$ and vertical interval of $2 \mathrm{~km}$ from depth 6 to $60 \mathrm{~km}$. In calculation of Green's functions, the Küpper wavelet with a duration of $1 \mathrm{~s}$ was employed. The "Seismic Analysis Code" (SAC; Goldstein and Snoke 2005; Helffrich et al. 2013) was used to store simulated seismograms and conduct a part of signal processing. We discarded the source grids within seawater column in Green's function evaluation and stations with epicentral distances equal to or larger than $550 \mathrm{~km}$. Approximately 13000000 Green's function SAC files from 49279 source grids to 15 F-net stations were obtained by conducting 45 reciprocal calculations. Each reciprocal calculation required 247 GB of computer memory and a wall-clock time of $1 \mathrm{~h}$ by parallel computing with 432 cores of the computer system of Earthquake and Volcano Information
Center at the Earthquake Research Institute, the University of Tokyo.

We choose F-net stations within epicentral distances between 100-400 km from the initial epicenter, obtained from the F-net MT catalog. A set of Green's functions at the source grids, which were located in $\pm 0.4^{\circ}$ grids from the initial epicenter and distributed at depths between 6 and $60 \mathrm{~km}$, were selected for grid search inversion. To apply band-pass filter and integration stably, we used 10-min F-net velocity seismograms from three minutes before the initial origin minutes. A $200 \mathrm{~s}$ time window for each CMT inversion was adopted. CMT inversions were conducted at every $1 \mathrm{~s}$ within $\pm 1 \mathrm{~min}$ from the origin minute to determine the centroid time. Time shifts, which adjust travel time differences between observed and synthetic seismograms at each station, were not permitted during grid search inversion, despite typical 1D MT routines such as the F-net MT system, enabling time shifts at each station between synthetic and observed seismograms. After CMT inversions, we obtained seismic moments and focal mechanisms at all possible spatial and temporal source grids. Then, to identify the optimal solution from all CMT solutions, we evaluated variance reductions (VRs) between the observed and synthetic displacement seismograms for periods of 25-100 s. If there was a perfect match between the observations and synthetics, the VR is $100 \%$. The maximum VR solution was 
considered the optimal solution, providing the optimal centroid location, depth, time, focal mechanism, and seismic moment. Other technical details of CMT inversions using the 3D model and the evaluation of Green's functions are described in Takemura et al. (2020).

We conducted forward simulations of ground motion in the Kanto region to investigate the effects of CMT solutions on long-period ( $>5 \mathrm{~s}$ ) ground motion using CMT solutions based on the 3D model. A more realistic velocity model, including velocity layers with $V s$ slower than $1.5 \mathrm{~km} / \mathrm{s}$, should be used in simulations of longperiod ground motion. As such, the model in long-period ground motion simulations included all sedimentary layers of the JIVSM listed in Table 1 . The model covered an area of $480 \times 480 \times 100 \mathrm{~km}^{3}$ (red dotted rectangle in Fig. 2a), which was discretized by grid intervals of $0.2 \mathrm{~km}$ in the horizontal direction and $0.1 \mathrm{~km}$ in the vertical direction. Simulated seismograms were evaluated at the F-net and MeSO-net stations within the calculation region (red dotted rectangle in Fig. 2a). The source parameters for events $\mathrm{a}, \mathrm{b}$, and $\mathrm{A}-\mathrm{C}$ are listed in Table 3. The centroid locations, times, and moment tensors from CMT solutions based on the 3D model were used for the listed earthquakes. The source time functions were characterized by the Küpper wavelet, and durations were expected by the empirical relationship between seismic moments and rupture durations (Kanamori and Brodsky 2004). Each simulation of long-period ground motion required $1190 \mathrm{~GB}$ computer memory and $4 \mathrm{~h}$ computation time; simulations were performed by parallel computing with 64 nodes of the Fujitsu PRIMERGY CX600M1/CX1640M1 (Oakforest-PAC) in the Information Technology Center, University of Tokyo.

\section{Results: 3D CMT solutions of moderate earthquakes beneath Kanto region}

Figure $2 b-d$ show an example of the 3D CMT inversion. The optimal solution for an earthquake on June 8,2017 is a low-angle $\left(22^{\circ}\right)$ thrust faulting at a depth of $48 \mathrm{~km}$, deeper the upper surface $(40 \mathrm{~km})$ and close to the oceanic Moho $(48 \mathrm{~km})$ of the Pacific Plate. The
F-net MT solution of this earthquake was also a similar focal mechanism; however, its centroid depth was slightly $(2 \mathrm{~km})$ deeper than that of our solution (see numbers above focal spheres in Fig. 2b). The spatial variation of the VRs at each source grid is illustrated in Fig. 2c. The resolution against centroid time is shown in Additional file 1: Figure S1. Although the optimal depth was very close to the upper surface of the Pacific Plate, high $(>80 \%)$ VR solutions appeared at a wider depth range $(36-56 \mathrm{~km})$. These features are similar to CMT solutions in the Hyuga-nada region, southwest Japan (Fig. 4 of Takemura et al. 2020). The centroid depth constraint is also not high for shallower crustal earthquake (Additional file 1: Figure S2). The synthetic seismograms of the optimal solution accurately reproduce the observations. We also showed CMT solution of this earthquake using periods of 10-100 s (Additional file 1: Figure S3). As similar to Hejrani and Tkalčić (2020), we confirmed that broader period analysis is important for constraining centroid depths. However, we employed the period band of 25-100 s for CMT inversions because the optimal solutions were not changed and the maximum VR was smaller than that for periods of 25-100 s.

We obtained 74 CMT solutions for shallow earthquakes $(<50 \mathrm{~km})$ with an $M w$ of 4.2-6.3; Fig. 3a illustrates the spatial distribution of these CMT solutions. All parameters for these CMT solutions are available from the data repository site (https://doi.org/10.5281/ zenodo.3926884). Hereafter, we simply call CMT solutions based on the local 3D model as "3D CMT solutions."

Cross-sections of profiles A and B are also plotted at the bottom of Fig. 3a. Along profile A (around $37.0^{\circ} \mathrm{N}$ ), distributions of CMT solutions between 3D and 1D catalogs show different futures. However, unfortunately, detailed discussions are difficult because of the lack of seismicity studies by ocean bottom seismometers along profile A. At the north region of profile A (around $37.5^{\circ} \mathrm{N}$ ), Shinohara et al. (2005) detected earthquakes of magnitudes ranging from 0.8 to 4.2 from 8

\footnotetext{
(See figure on next page.)

Fig. 2 Settings and an example of 3D CMT inversion in the Kanto region. a Simulation settings to evaluate Green's functions. The regions enclosed by the blue dashed and red dotted lines represent the horizontal coverage of the simulation model regions for evaluating Green's functions and long-period ground motion simulations, respectively. The triangles and crosses in the map denote the locations of the F-net stations and the assumed source grids, respectively. (b-d) an example of a CMT solution for an earthquake on June 8, 2017, the location and depth of the optimal solution, used stations, and depth variations of optimal solutions at each source grid. Colors of the focal mechanisms reflect values of variance reduction between observed and synthetic displacements in the 25-100 s period band. The numbers above the optimal solutions in (b) are the optimal centroid depths. The grey focal mechanism in (b) is the F-net MT solution of this earthquake. The blue triangles in (b) are used F-net stations. (c) Spatial variations of VRs along latitude-depth and longitude-depth planes. (d) Examples of comparisons between observed and synthetic displacements in the 25-100 s period band. Gray solid and blue dotted lines are the observed and synthetic seismograms, respectively. Synthetic seismograms were evaluated by assuming the optimal solution. Amplitudes at each station were normalized by the maximum amplitude of observed and synthetic three-component displacement waveforms
} 

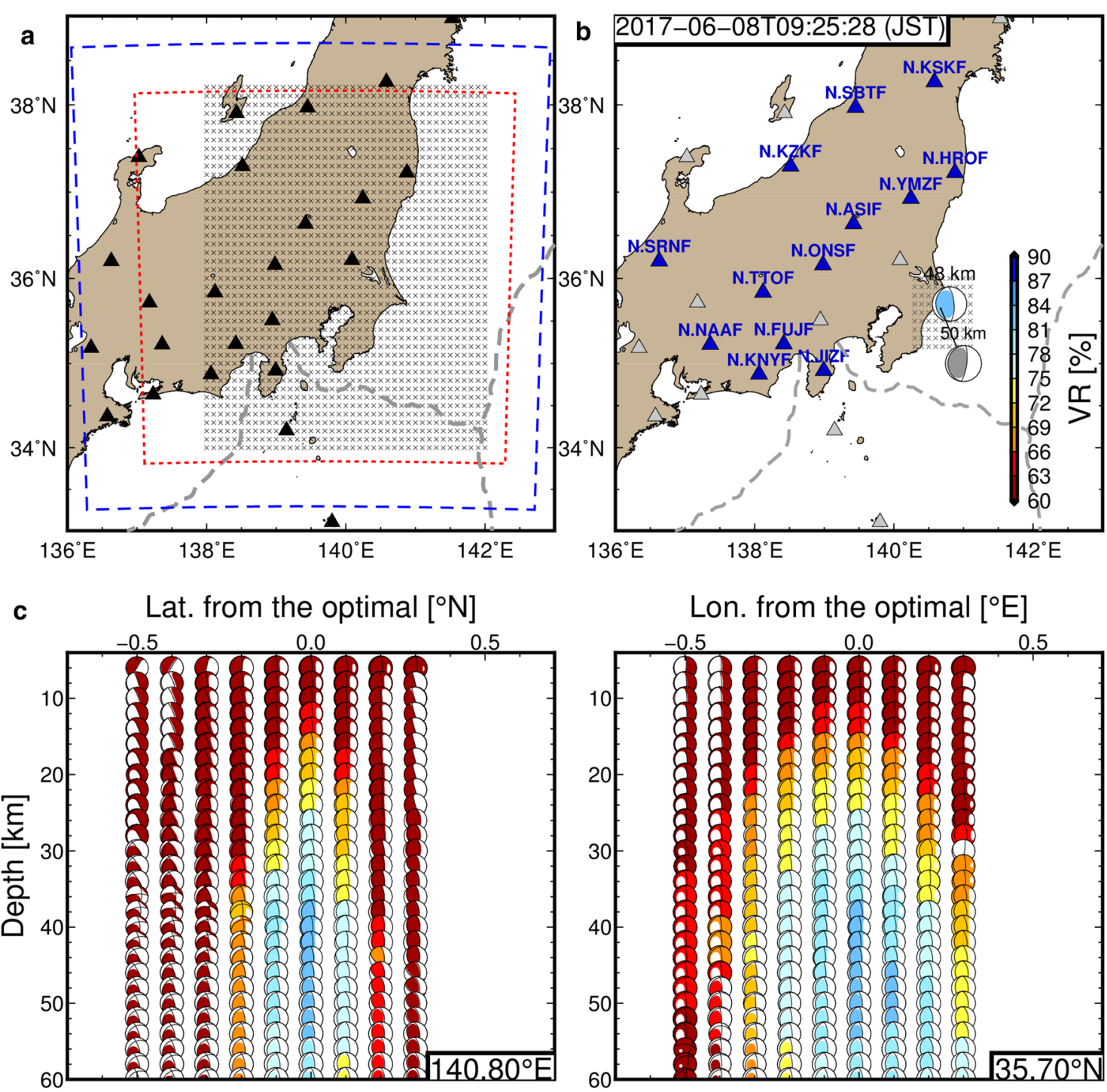

Lon. from the optimal $\left[{ }^{\circ} \mathrm{E}\right]$

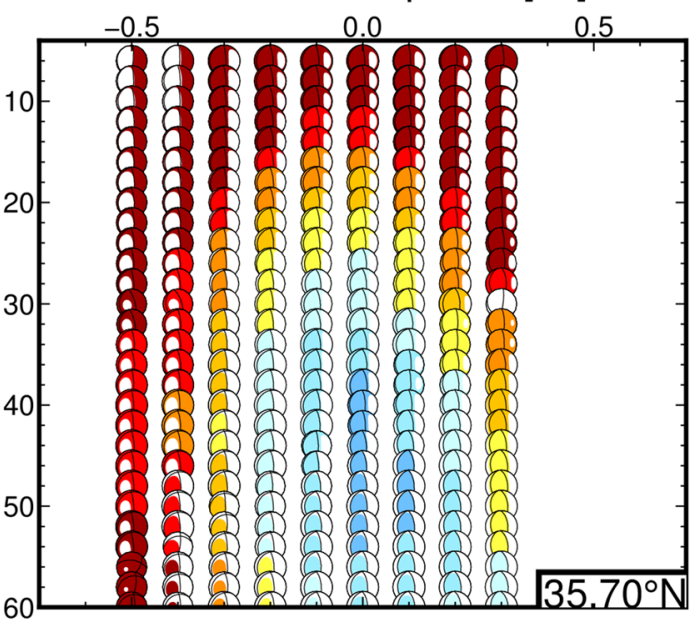

d
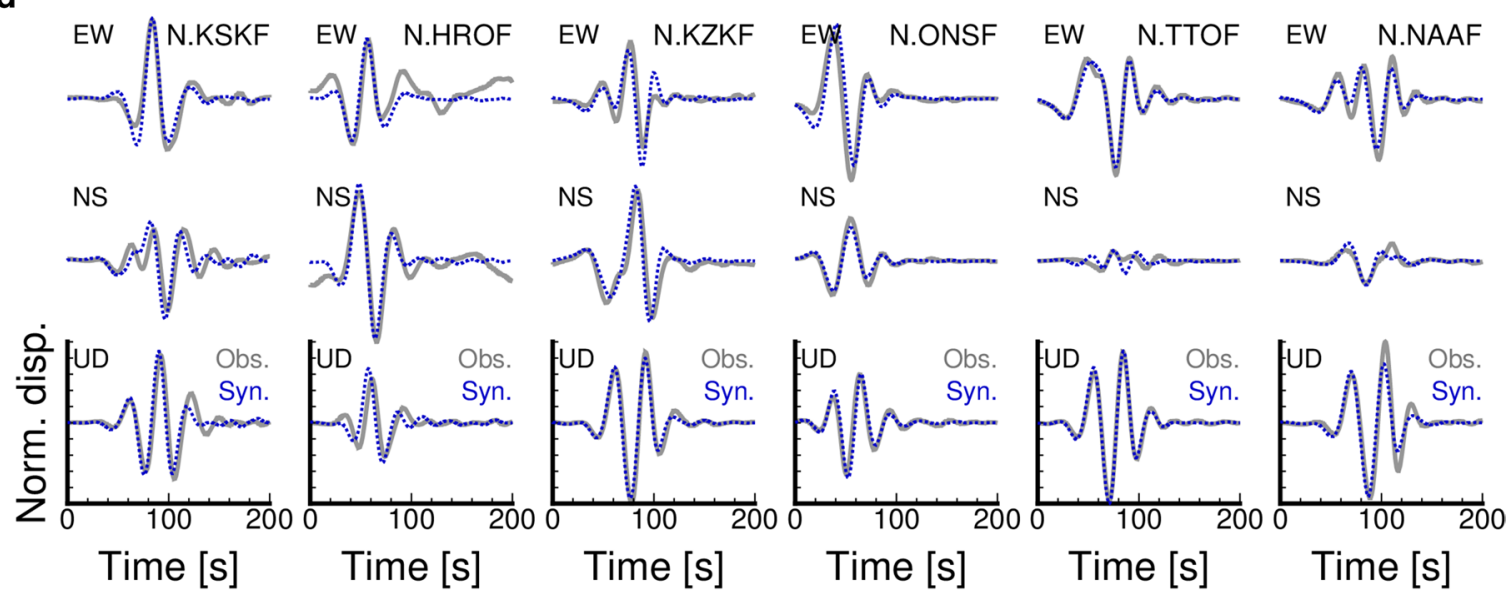
Table 1 Physical parameters of each layer in JIVSM

\begin{tabular}{|c|c|c|c|c|c|c|}
\hline & $V_{P}[\mathrm{~km} / \mathrm{s}]$ & $V_{s}[\mathrm{~km} / \mathrm{s}]$ & $\rho\left[\mathrm{kg} / \mathrm{m}^{3}\right]$ & $\mu[\mathrm{GPa}]$ & $Q_{p}$ & $Q_{S}$ \\
\hline Air & 0.0 & 0.0 & 0.001 & 0.0 & $10^{10}$ & $10^{10}$ \\
\hline Seawater & 1.5 & 0.0 & 1.04 & 0.0 & $10^{6}$ & $10^{6}$ \\
\hline Sedimentary layer 1 & 1.8 & 0.5 & 1.95 & 0.49 & 170 & 100 \\
\hline Sedimentary layer 3 & 2.3 & 0.9 & 2.10 & 1.70 & 340 & 200 \\
\hline Sedimentary layer 4 & 3.0 & 1.5 & 2.25 & 5.06 & 510 & 300 \\
\hline Basement & 5.5 & 3.2 & 2.65 & 27.1 & 680 & 400 \\
\hline Upper crust & 5.8 & 3.4 & 2.70 & 31.2 & 680 & 400 \\
\hline Lower crust & 6.4 & 3.8 & 2.80 & 40.0 & 680 & 400 \\
\hline Upper mantle & 7.5 & 4.5 & 3.20 & 64.8 & 850 & 500 \\
\hline \multicolumn{7}{|l|}{ Philippine Sea plate } \\
\hline Oceanic crust layer 2 & 5.0 & 2.9 & 2.40 & 20.2 & 340 & 200 \\
\hline Oceanic crust layer 3 & 6.8 & 4.0 & 2.90 & 46.4 & 510 & 300 \\
\hline Oceanic Mantle & 8.0 & 4.7 & 3.20 & 70.7 & 850 & 500 \\
\hline \multicolumn{7}{|l|}{ Pacific Plate } \\
\hline Oceanic crust layer 2 & 5.4 & 2.8 & 2.60 & 20.4 & 340 & 200 \\
\hline Oceanic crust layer 3 & 6.5 & 3.5 & 2.80 & 34.3 & 510 & 300 \\
\hline Oceanic Mantle & 8.1 & 4.6 & 3.40 & 71.9 & 850 & 500 \\
\hline
\end{tabular}

The air and seawater layers were treated as being the same, following Maeda et al. (2017). The $P$-wave velocity $\left(V_{\rho}\right), S$-wave velocity $\left(V_{S}\right)$, density $(\rho)$, rigidity $(\mu)$ and inelastic attenuation $\left(Q_{P}\right.$ and $\left.Q_{S}\right)$ are listed

August to 24 August 1997 using temporal ocean bottom seismometers. According to their results, the reverse faulting solutions off the Fukushima in our CMT cata$\log$ (blue focal spheres) could be considered as the lower seismicity in the double seismic zone within the subducting Pacific slab. In our analysis period, many shallow $(\sim 20-30 \mathrm{~km})$ small earthquakes were listed in the JMA catalog, but no CMT solutions for moderate earthquakes were located in the upper seismicity in the double seismic zone. Along with profile B, many earthquakes occurred just below the upper surface of the Pacific Plate. To validate our CMT solutions, especially in epicenter locations and depths, we compared the hypocenter distributions based on temporal ocean bottom seismometers (Ito et al. 2017a, b), which covered the area around the profile $B$. This seismicity was also confirmed in their hypocenter distribution.

Although we could not compare detailed hypocenter distribution studies in other offshore regions (e.g., along profile $\mathrm{A}$, around $36.0^{\circ} \mathrm{N}$ ), we consider that the 3D CMT inversion works well in offshore region of the Kanto region. The percentages of isotropic, compensated linear vector dipole (CLVD), and double-couple (DC) components in both catalogs are illustrated in Additional file 1: Figure S4. Differences between our and F-net catalogs could be caused by differences in velocity model and moment tensor inversion settings. In the F-net routine system, the isotropic component is not considered.

\section{Differences between 3D CMT and F-net MT catalogs}

The F-net solutions of corresponding earthquakes are also plotted in Fig. 3b. Spatial distributions of both catalogs seem to be similar. To quantitatively evaluate differences between the 3D CMT in this study and the F-net MT catalogs, we calculated cross-correlation coefficients of $P$-wave radiation patterns (e.g., Kuge and Kawakatsu 1993; Helffrich 1997), depth, and $M w$ differences between the 3D CMT and F-net MT catalogs (Fig. 4). A large negative value (-0.6) of cross-correlation coefficients only appeared in a solution for an earthquake on February 23, 2019. Only 4 F-net stations (N.JIZF, N.KZKF, N.YMZF, and N.KSKF; see Fig. 2b) were applicable for the CMT inversion of this earthquake because of the low signal-to-noise ratio (SNR) for 25-100 s periods. Additionally, the VR of the 3D CMT solution was not high $(\sim 57 \%)$. With the exception of this event, differences in focal mechanisms and centroid depths were not significant compared to offshore earthquakes along the Nankai Trough (Fig. 8 of Takemura et al. 2020).

On the other hand, we found that the $M w$ values based on the 3D CMT were systematically smaller than those of the F-net MT catalog (Fig. 4c). The $M w$ values are very important for ground motion simulations because values of seismic moments are directly related to the amplitude of the simulated ground motion. Using the 3D CMT catalog along the Nankai Trough (Takemura et al. 2020; https ://doi.org/10.5281/zenodo.3674161), we also evaluated 

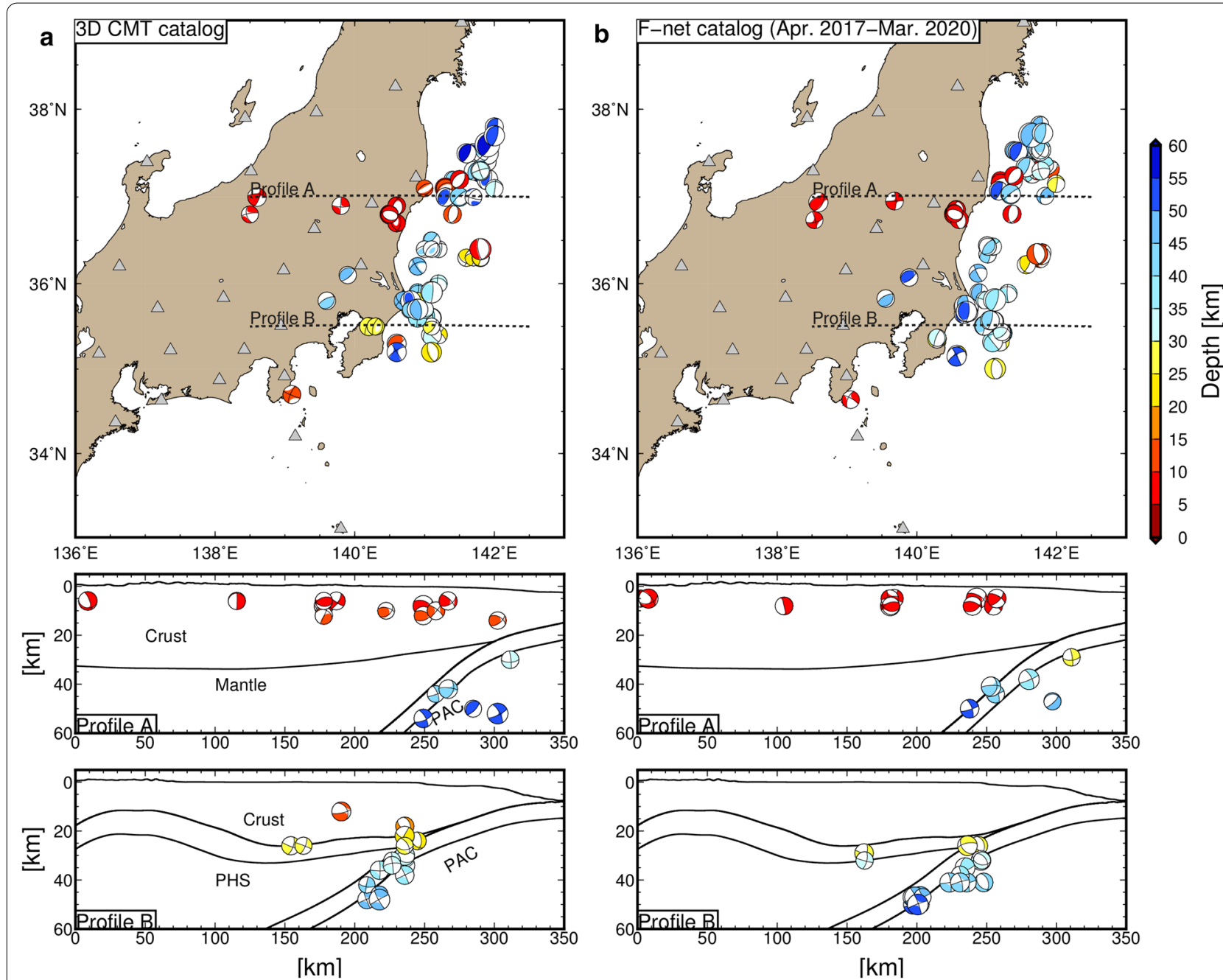

Fig. 3 Results of 3D CMT inversion in the Kanto region. a 3D CMT catalog (this study), and $\mathbf{b}$ F-net MT catalog. Upper panels are map views of focal mechanisms. The colors represent the estimated centroid depth. The bottom panels show cross-sections along profiles A and B. In the bottom panels, topography, Moho, the upper surface of subducting plates, and the oceanic Moho are plotted

the differences in the $M w$ between 3D CMT and F-net MT solutions. We found both larger and smaller $M w$ values compared to the F-net catalog in the Nankai region (Fig. 5). In the Kanto and Nankai regions, the differences in $M w$ for offshore earthquakes were larger than those of onshore earthquakes; these differences may be caused by 3D heterogeneities.

To investigate the cause of these $M w$ differences, we conducted ground motion simulations for $M w 4.36$ earthquake on 10:02:45 (JST) November 17, 2017 (Event a) and $M w 4.35$ earthquake on 19:56:05 (JST) on August 6, 2018 (Event b). Using the 3D CMT method, Events a and $b$ were located just below the upper surface of the oceanic crust layer 2 and the boundary between oceanic crust layers 2 and 3 of the Pacific Plate, respectively. The $M w$ differences for events $\mathrm{a}$ and $\mathrm{b}$ were -0.31 and -0.25 , respectively, and the estimated seismic moments of the
3D CMT solutions were approximately $35 \%$ and $42 \%$ of the F-net 1D solutions, respectively. We conducted simulations using the same source models and three different heterogeneous models; the JIVSM (Koketsu et al. 2012), the JIVSM without sediments, and the F-net 1D model (Kubo et al. 2002). The source models were the optimal solutions of 3D CMT inversion for two earthquakes (Events $\mathrm{a}$ and $\mathrm{b}$ in Table 3).

Figure 6 compares the simulated and observed vertical velocity seismograms. Two F-net stations were selected, and other simulation results were stored at https://doi. org/10.5281/zenodo.3926888. We found that simulation results using the JIVSM and the JIVSM without sediments reproduced observed F-net seismograms, with the exception of the N.JIZF seismograms for the JIVSM without sediments. This suggests that the effects of lowvelocity sediments around the Kanto region on CMT 

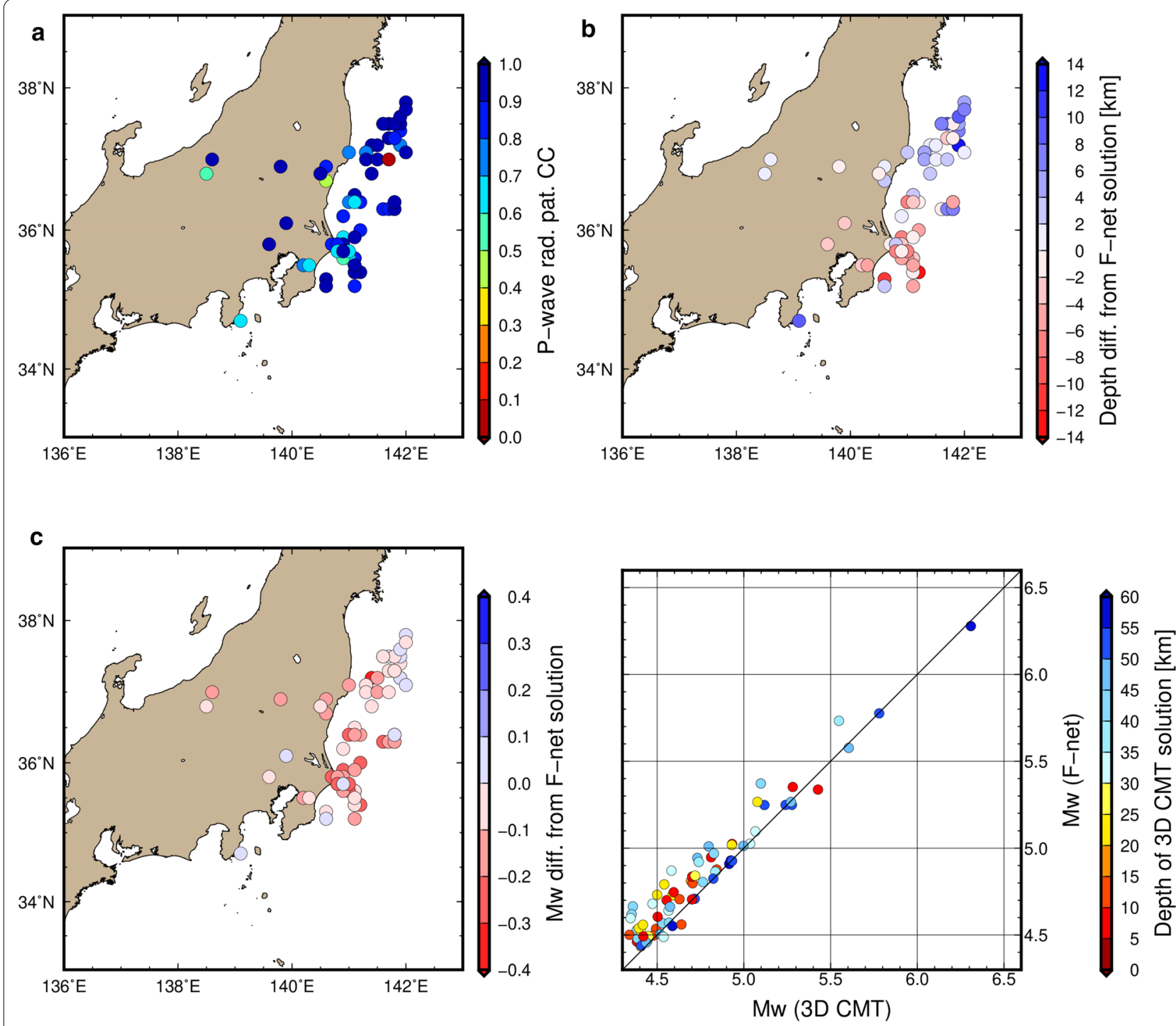

Fig. 4 Differences between 3D CMT and F-net MT catalogs in the Kanto region. a Cross-correlation of P-wave radiation patterns (e.g., Kuge and Kawakatsu 1993; Helffrich 1997) between 3D CMT and F-net MT catalogs. b Depth differences and c Mw differences from F-net MT solutions

inversion using long-period (25-100 s) seismograms are minor. On the other hand, in the Nankai region, thick low-velocity accretionary prism has significant influence on seismograms even for periods of $25-100 \mathrm{~s}$. This difference could be explained by differences in thickness between the Kanto basin $(\sim 3 \mathrm{~km})$ and accretionary prism $(\sim 5 \mathrm{~km})$. Because the Kanto Basin and marine sediments exist along the path from event $b$ to N.JIZF, the difference in waveforms of N.JIZF for periods of 10-50 s might appear. Around the Nankai Trough, a thicker $(>5 \mathrm{~km})$ accretionary prism has a significant influence on surface waves even for periods longer than $20 \mathrm{~s}$, and consequently the affects the results of CMT inversions and ground motion simulations (e.g., Nakamura et al. 2015; Takemura et al. 2018a, b, 2019a, 2019b, 2020).
On the other hand, the amplitudes of simulation seismograms with a similar source and the F-net 1D model were approximately $35-45 \%$ of the observed amplitudes. The effects of the Kanto Basin have a minor influence on ground motion at outcrop rock sites (F-net), and differences in mechanisms and depths compared with F-net solutions that are not significant. This difference could be explained by differences in heterogeneities around the seismic source. The 3D CMT solutions of events $a$ and $b$ were located just beneath the upper surface of the oceanic crust layer 2 and near the boundary between oceanic crust layers 2 and 3 of the Pacific Plate, respectively. In the JIVSM (Table 1), the rigidities of source areas for both events were 20.4-34.3. In contrast, the rigidity at depths between 33 and $100 \mathrm{~km}$ was a uniform value (63.7 

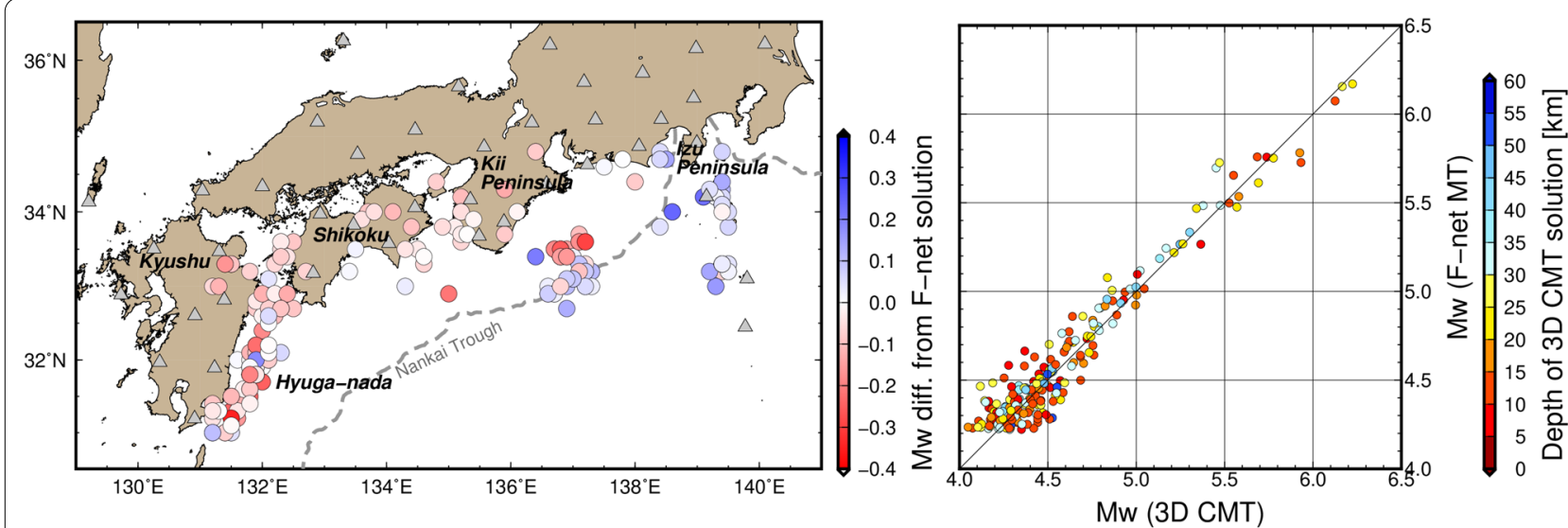

Fig. 5 Differences in Mw values between F-net MT and 3D CMT solutions along the Nankai Trough. The 3D CMT catalog along the Nankai Trough was referred from Takemura et al. (2020)

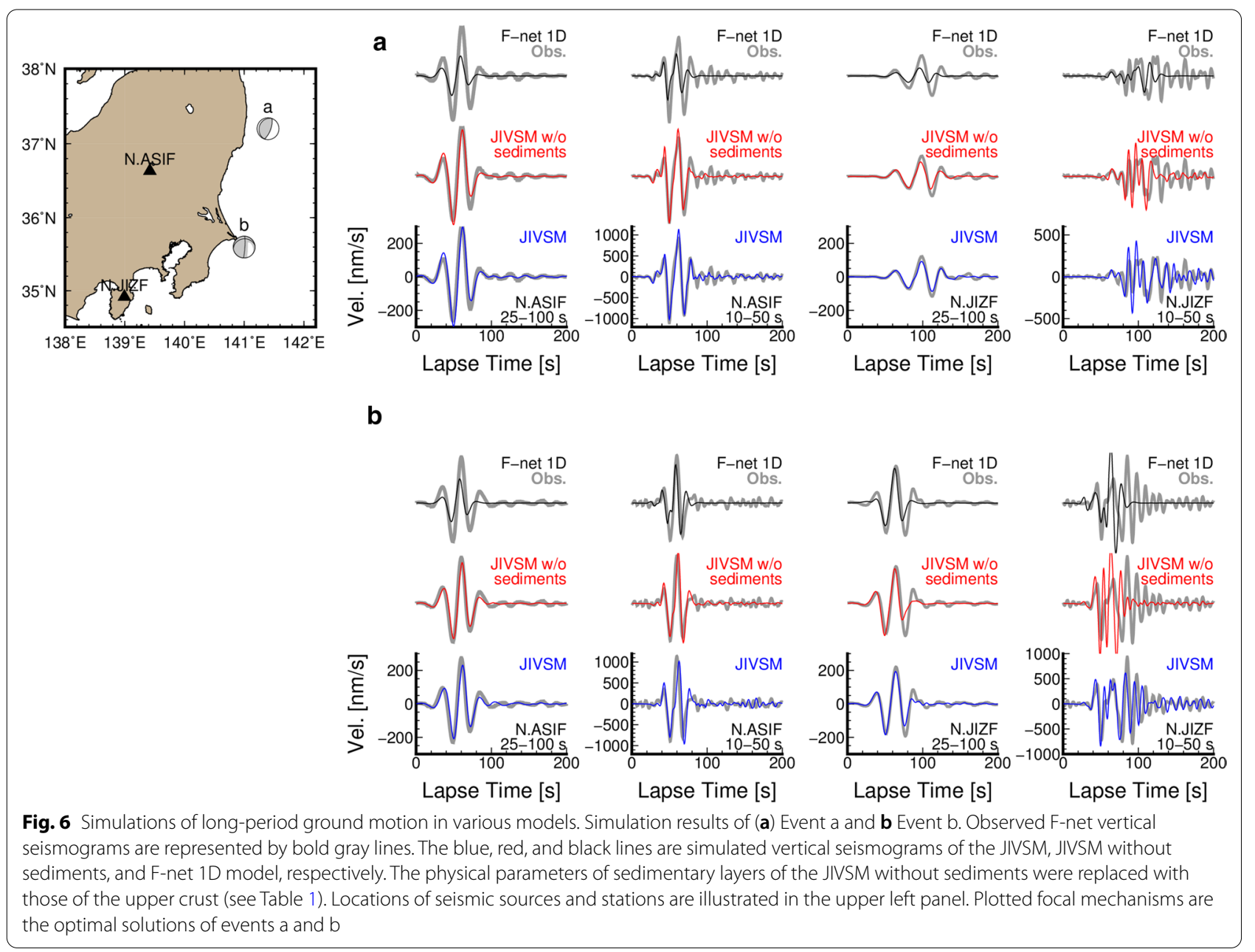


Table 2 F-net 1D velocity model. The physical parameters were referred from Kubo et al. (2002)

\begin{tabular}{|c|c|c|c|c|c|c|}
\hline $\begin{array}{l}\text { Thickness (Depth) } \\
{[\mathrm{km}]}\end{array}$ & $V_{P}[\mathrm{~km} / \mathrm{s}]$ & $V_{s}[\mathrm{~km} / \mathrm{s}]$ & $\rho\left[\mathrm{kg} / \mathrm{m}^{3}\right]$ & $\mu[\mathrm{GPa}]$ & $Q_{p}$ & $Q_{S}$ \\
\hline $3(0-3)$ & 5.5 & 3.14 & 2.3 & 22.7 & 600 & 300 \\
\hline $15(3-18)$ & 6.0 & 3.55 & 2.4 & 30.2 & 600 & 300 \\
\hline $15(18-33)$ & 6.7 & 3.83 & 2.8 & 41.1 & 600 & 300 \\
\hline $67(33-100)$ & 7.8 & 4.46 & 3.2 & 63.7 & 600 & 300 \\
\hline $125(100-225)$ & 8.0 & 4.57 & 3.3 & 67.7 & 600 & 300 \\
\hline $100(225-325)$ & 8.4 & 4.80 & 3.4 & 78.3 & 600 & 300 \\
\hline $100(325-425)$ & 8.6 & 4.91 & 3.5 & 84.4 & 600 & 300 \\
\hline- & 9.3 & 5.31 & 3.7 & 104 & 600 & 300 \\
\hline
\end{tabular}

GPa; Table 2) in the F-net 1D model. The differences in rigidities around source regions between the JIVSM and the F-net 1D model correspond to differences in seismic moments between the 3D CMT and F-net MT solutions (34-42\%).

We additionally simulated long-period ground motions for CMT solutions with $M w$ differences equal to or smaller than -0.2 . Simulated earthquakes are listed in Additional file 1: Table S1. Amplitude differences at each station were calculated by dividing maximum simulated amplitudes in the F-net 1D model by those in the JIVSM. Maximum amplitudes were measured using vertical seismograms for periods of 25-100 s. At almost stations, amplitudes using the JIVSM were larger than those using the F-net 1D model (Fig. 7a). Due to structural differences and radiation pattern of the assumed sources, relationship between $M w$ and amplitude differences exhibited simple linear trend, but amplitude differences tended to increase with decreasing $M w$ difference $(-0.2$ to -0.3$)$. We also compared the relationship between $M w$ differences and rigidity structures (Fig. $7 \mathrm{~b}, \mathrm{c}$ ). The rigidity differences were evaluated by differences of the JIVSM rigidities at centroid depths from the F-net 1D model. We confirmed the positive correlation between rigidity and $M w$ differences. In the Nankai region (Fig. 7c), because centroid depths were changed in the cases of offshore earthquakes (Fig. 8 of Takemura et al. 2020), the values of $M w$ differences were scattered. As such, it may be concluded that the major cause of differences in seismic moments between the 3D CMT and F-net 1D MT solutions is the difference in rigidity around the source areas.

For the Nankai Trough, both overestimations and underestimations of seismic moments compared to the F-net catalog were observed (Fig. 5). Large $M w$ differences only appeared in the offshore region, where many intraslab and interplate earthquakes occurred. In particular, intraslab earthquakes along the Nankai Trough occurred within the low-velocity oceanic crust and highvelocity oceanic mantle (see Figs. 5 and 6 of Takemura et al. 2020), not modeled in the F-net 1D model. The difference in $M w$ values along the Nankai Trough could also be explained by the differences in heterogeneous structures between the 3D and 1D models.

In the F-net routine system, the origin times and epicenters were fixed as those in the JMA unified hypocenter catalog, and time shifts between observed and synthetic seismograms at each station were enabled. Miyoshi et al. (2017) notes that prior to estimating structural properties, the re-evaluation of centroid times for F-net MT solutions should be required to obtain suitable waveform inversion results. In this study, we found that the estimation of seismic moments was affected by the rigidity structure around the source region. The difference in the estimation of seismic moments directly impacts the amplitude of ground motion simulations. The amplitude of ground motion simulation is important to evaluate seismic hazards and estimate structural properties along propagation paths. The 3D CMT catalog allow us to directly conduct $3 \mathrm{D}$ ground motion simulations without adjusting source parameters, such as centroid depth, focal mechanism and seismic moment.

The earthquakes with large $M w$ differences tend to be located within the oceanic crust and mantle (Figs. 4 and 5). The precise fault size evaluation is one of important issues for evaluating seismicity within the slab and expecting seismic hazard due to intraslab earthquakes. The 3D CMT catalog can provide precise values of seismic moments of interaslab earthquakes because the effects of 3D heterogeneous rigidity structures can be evaluated by numerical simulations during preparing Green's function dataset.

\section{Long-period ground motion simulations in the Kanto region}

By using our 3D CMT solutions based on the JIVSM, we conducted numerical simulations of long-period ground motions and compared with the observed seismograms. For the SNR of the MeSO-net for periods longer than 

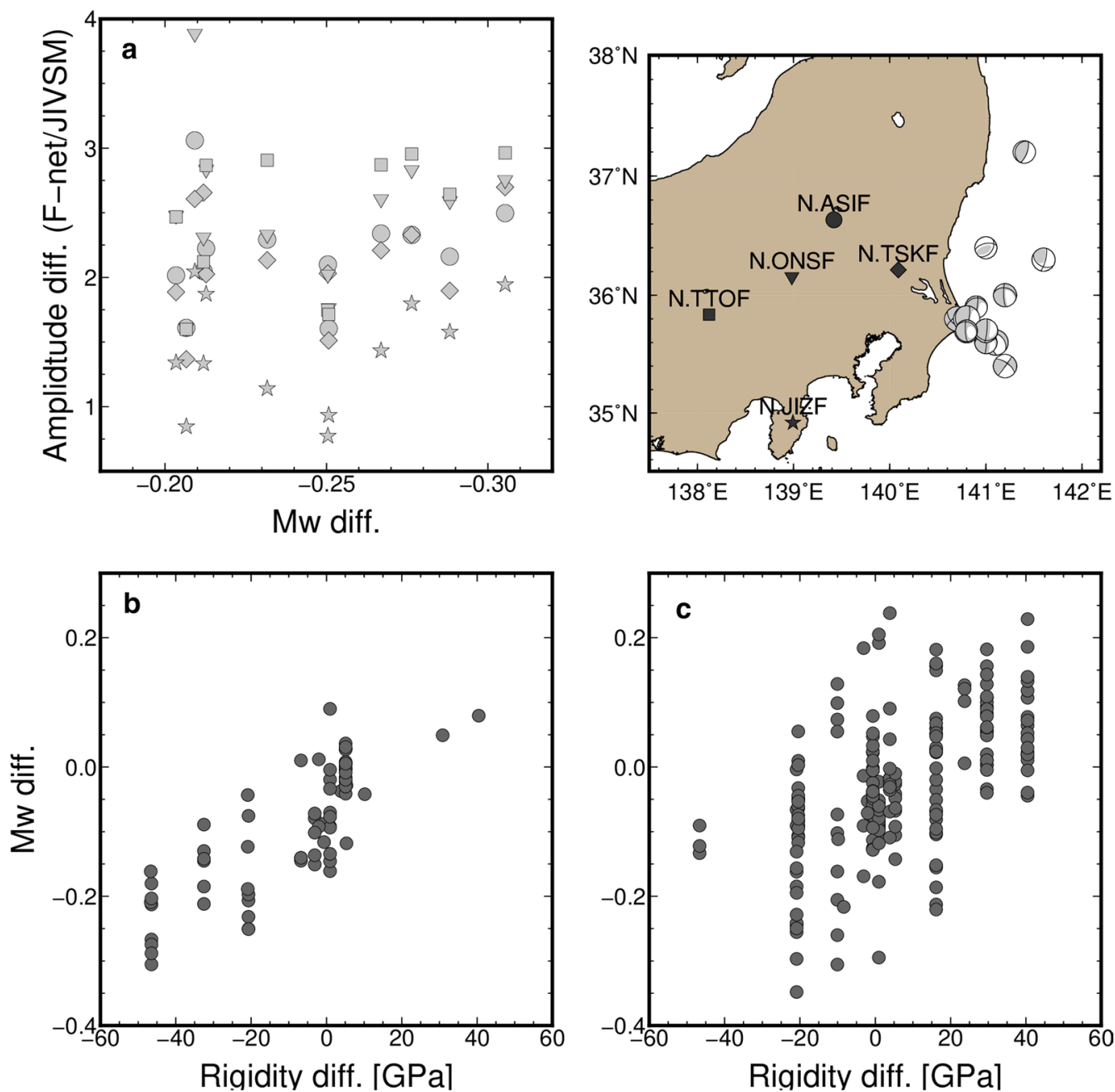

Fig. 7 Amplitude and Mw differences between the JIVSM and F-net 1D model. a Amplitude differences of simulation results from the JIVSM and F-net 1D models. Circle, diamond, inverse triangle, square, and star represent amplitude ratio or station location of N.ASIF, N.TSKF, N,ONSF, N.TTOF, and N.JIZF, respectively. Amplitudes ratios were calculated by dividing maximum amplitudes of simulations using the F-net 1D model by those using the JIVSM. Maximum amplitudes were measured using vertical seismograms for periods of 25-100 s. The relationships between $M W$ differences and rigidity structures in (b) Kanto and (c) Nankai regions. The rigidity differences were evaluated by differences of the JIVSM rigidities at centroid depths from the F-net 1D model. The Mw differences in (c) was made from the data of Takemura et al. (2020)

$5 \mathrm{~s}$, three earthquakes were selected with an $M w$ equal to or larger than 5.5 for simulations of long-period ground motion in the Kanto Basin. The source parameters of selected events $(\mathrm{A}-\mathrm{C})$ are listed in Table 3. Complete files of simulated velocity waveforms and wavefields are available online https://doi.org/10.5281/zenodo.3926888.

Figure 8 shows an example of simulated vertical velocity wavefields for the simulation of Event A at 40, 60, 80, $100,120,140,160$, and $180 \mathrm{~s}$ from the earthquake origin (movie file is also available from https://doi.org/10.5281/ zenodo.3926888). The seismic waves radiated from the source complicatedly propagate through the Kanto region. In the Kanto, Niigata, and offshore regions, the wavelengths and propagation speeds of the Rayleigh waves became shorter and slower due to low-velocity sediments. The energy of these shorter-wavelength components (i.e., long-period ground motion) was trapped within low-velocity sediments. Thus, the duration of long-period ground motion was elongated in the Kanto, Niigata, and offshore regions (lapse time of 180 s). Peak ground velocities (PGVs) were calculated by the vector sum of three-component filtered seismograms at the F-net and MeSO-net stations; the passband period was 5-30 s. Figure 9 shows the spatial distributions of PGVs for each event. With the exception of Event $\mathrm{C}$, the simulations were able to roughly reproduce the observed 

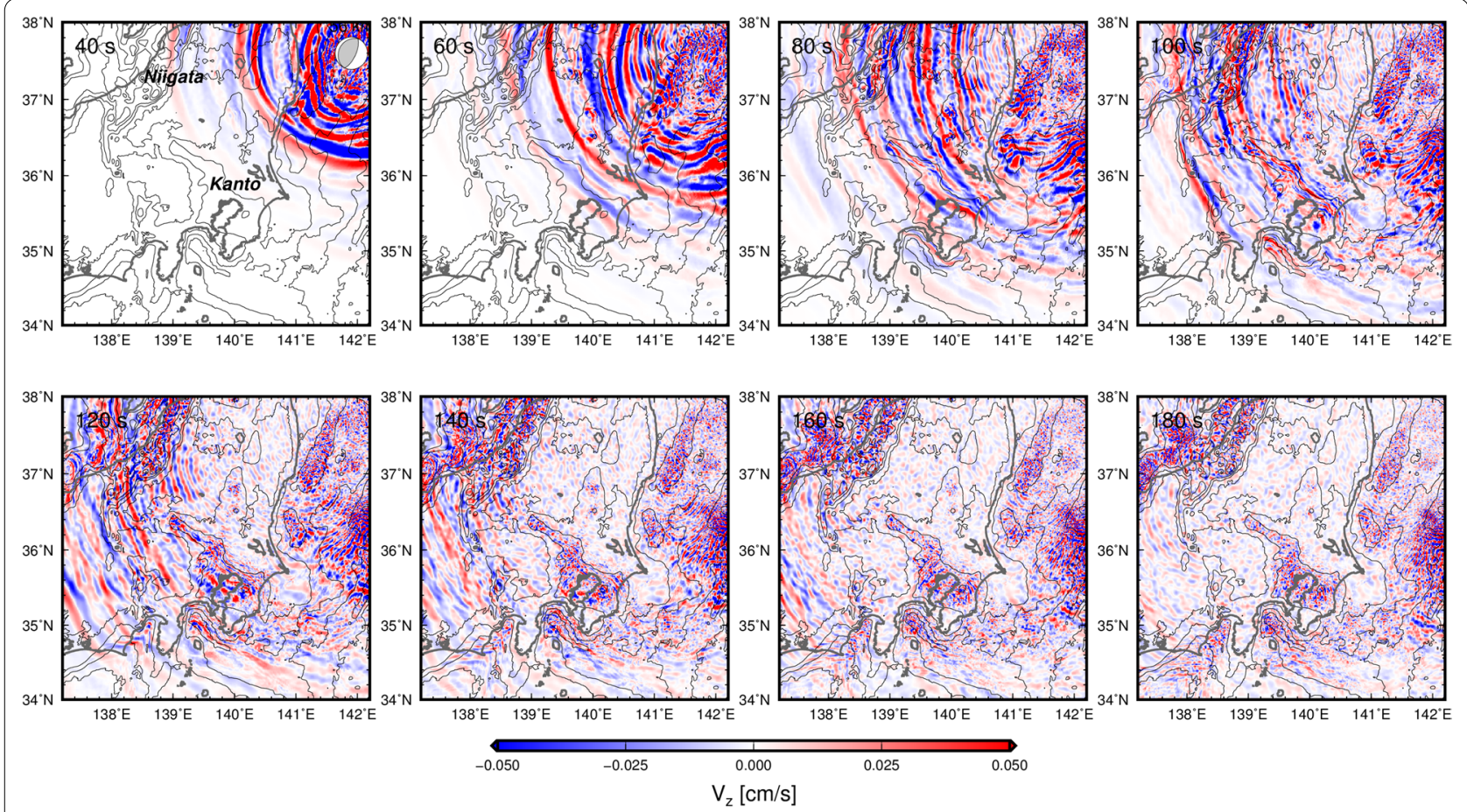

Fig. 8 Snapshots of simulated vertical velocity wavefield for Event A. The numbers at the left-top corner are lapse times from the earthquake origin. The contour lines are the JIVSM bedrock depths at $2 \mathrm{~km}$ intervals

Table 3 Source parameters of long-period ground motions

\begin{tabular}{|c|c|c|c|c|c|c|c|c|c|c|c|}
\hline & Lon. $\left[^{\circ}\right]$ & Lat. $\left[^{\circ}\right]$ & Depth [km] & $M_{r r}$ & $M_{\theta \theta}$ & $M_{\varphi \varphi}$ & $\mathrm{M}_{\mathrm{r} \theta}$ & $M_{r \varphi}$ & $M_{\varphi \theta}$ & Exp. & Dur. [s] \\
\hline a & 141.4 & 37.2 & 44 & 3.365 & -0.118 & -1.848 & 1.191 & 3.131 & -0.649 & 22 & 1 \\
\hline$b$ & 141.0 & 35.6 & 32 & 2.659 & 0.623 & 2.077 & -0.707 & 3.068 & -1.249 & 22 & 1 \\
\hline A & 141.9 & 37.6 & 56 & 2.540 & -0.520 & -2.144 & 1.004 & 2.352 & -1.102 & 25 & 5 \\
\hline B & 141.1 & 36.0 & 36 & 1.128 & -0.696 & -0.711 & 0.055 & 2.408 & -0.210 & 24 & 3 \\
\hline C & 141.8 & 36.4 & 8 & -1.402 & -0.082 & 0.713 & -0.239 & 1.316 & -0.043 & 24 & 2 \\
\hline
\end{tabular}

Origin times of events $a, b, A, B$ and C were 10:02:45 JST on November 17, 2017, 19:56:05 JST on August 6, 2018, 19:23:01 JST on August 4, 2019, 03:23:54 JST on January 3, 2020, and 20:19:56 JST on February 6, 2020, respectively. Source durations were assumed using the empirical relationship between seismic moments and durations (Kanamori and Brodsky 2004)

features of PGVs. Large PGVs appeared in regions with bedrock depths greater than $3 \mathrm{~km}$.

Figures 10, 11, and 12 compare the filtered seismograms (15-30, 10-20, and 5-16 s) between observations and simulations. We selected two F-net stations and three MeSO-net stations. The selected MeSO-net stations are located at the site with deeper $(>3 \mathrm{~km}$ ) bedrock depths. Simulations reproduced the observed seismograms at two F-net stations (N.ASIF and N.JIZF), with the exception of the simulation results for Event $\mathrm{C}$ for periods of
5-16 s. These results suggest that these 3D CMT solutions have the ability to reproduce observed ground motion with sufficient accuracy for periods longer than $5 \mathrm{~s}$ at F-net stations, which are deployed at outcrop rock sites. Although the observed seismograms at MeSOnet stations were reproduced by the simulated seismograms for periods longer than $10 \mathrm{~s}$ with the exception of the later phases at E.YROM, the simulation results for 5-16 s periods could not explain the observed seismograms in the Kanto Basin. This period band includes the 


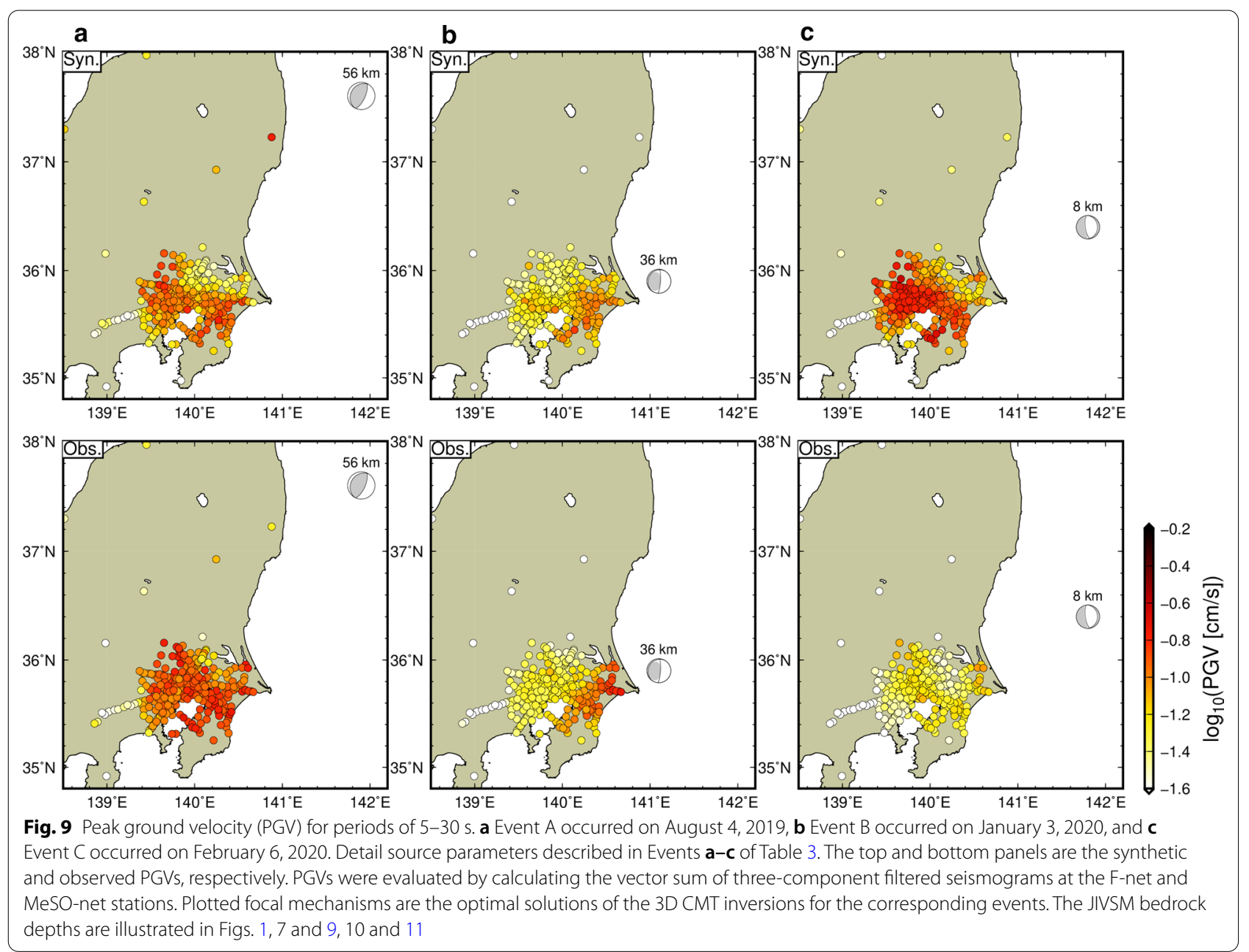

dominant period ( $\sim \mathrm{s}$ ) of long-period ground motions within the Kanto Basin (e.g., Yoshimoto and Takemura 2014). These seismogram discrepancies at the MeSOnet stations could be caused by the JIVSM sedimentary structure. For Event $\mathrm{C}$, because the centroid depth was $8 \mathrm{~km}$, the ground motion for $10-20$ and 5-16 s periods were affected by both the Kanto sedimentary basin and oceanic sediments from the epicenter to coastal regions. Thus, these sedimentary structures in the offshore region may decrease waveform fitness for this event. The overestimation of PGVs (Fig. 9c) may also be attributed to the models of the Kanto Basin and the oceanic sediments along propagation paths.

We also conducted simulations of long-period ground motions using F-net MT solutions. The correlation coefficients of $P$-wave radiation patterns for Events A-C are $0.99,0.91$, and 0.91 , respectively, and depth differences from F-net solutions are 9, -2 , and $-6 \mathrm{~km}$, respectively. Simulation results of F-net solutions (Additional file 1: Figures S5-7) could not reproduce observed seismograms, and discrepancies from observations could not be corrected by simple adjustment of seismic moments. This result implies that although differences in focal mechanisms and depths between our and F-net 1D catalogs were not so significant, these differences improved the reproducibility of broadband (5-100 s) observed seismograms at stations with/without the Kanto Basin. The 3D CMT catalog allows us to directly conduct the precise forward and inverse modeling of long-period ground motion without adjusting source models, 


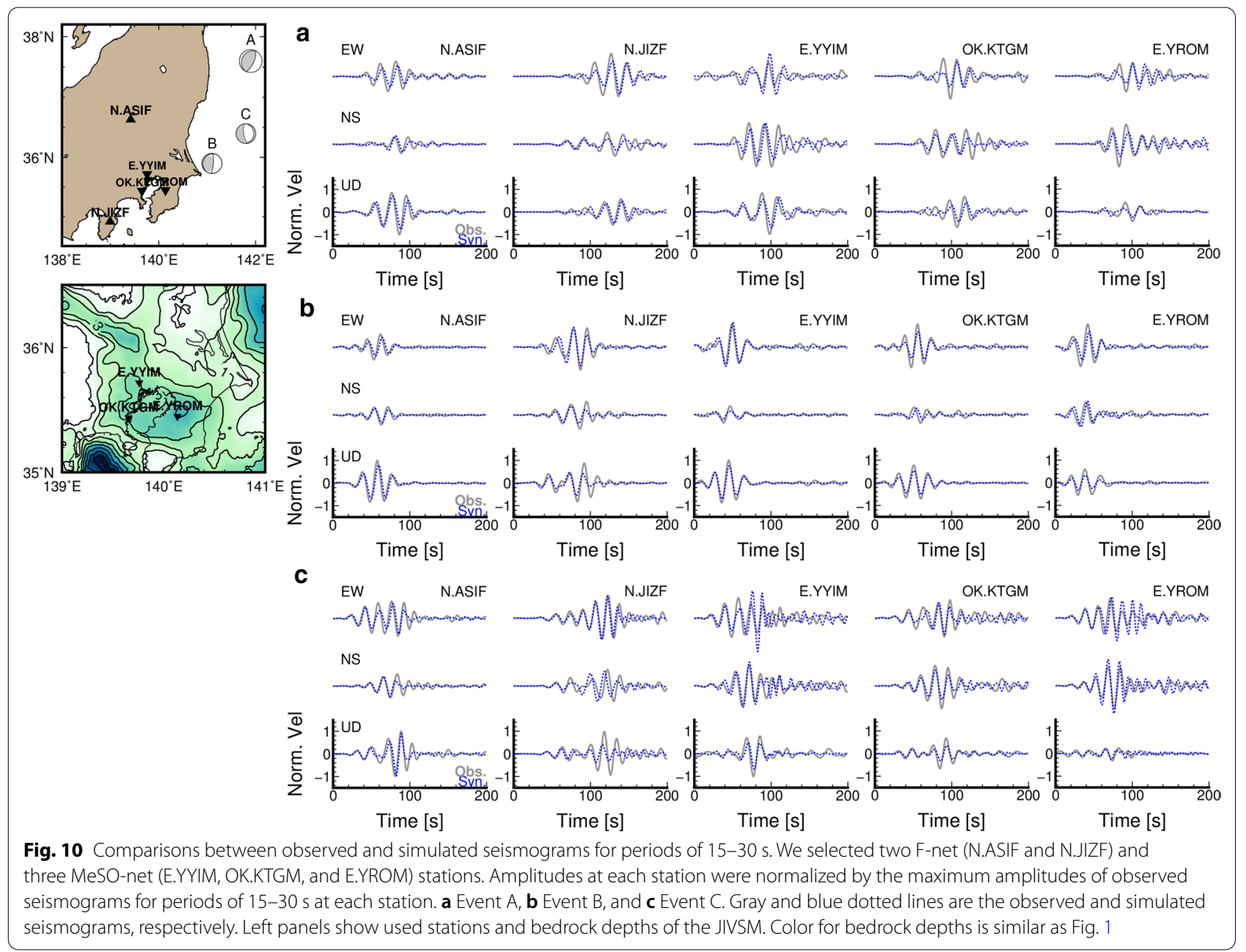

\section{Conclusions}

We conducted CMT inversions of moderate earthquakes in the Kanto region from April 2017 to March 2020. The estimated focal mechanisms and depths using the 3D CMT method were not significantly different from the corresponding F-net MT solutions. However, the $M w$ values were systematically smaller than those in the F-net catalog. Earthquakes with large $M w$ differences tended to be located within the subducting plate, i.e., intraslab earthquakes. Using numerical simulations with 3D and 1D velocity models, we concluded that the major cause for the $M w$ differences is the difference in rigidity between the $1 \mathrm{D}$ and $3 \mathrm{D}$ velocity models. The $3 \mathrm{D}$ subducting oceanic crust and mantle could not be modeled in the 1D CMT system.
The 3D CMT method provide precise values of seismic moments including the effects of 3D rigidity structure and thus, the 3D CMT catalog is important for evaluating characteristics of intraslab seismicity. The differences in the estimation of seismic moments directly affect the amplitude of ground motion simulations. The 3D simulation of an intraslab earthquake using the 1D CMT catalog could cause overestimations in the amplitude, even at outcrop rock sites. The 3D CMT solutions should be adopted for precise forward and inverse modeling of long-period ground motion simulations. The 3D CMT solutions can be directly used in ground motion simulations without adjusting source parameters, such as centroid depth, focal mechanism and seismic moment. 


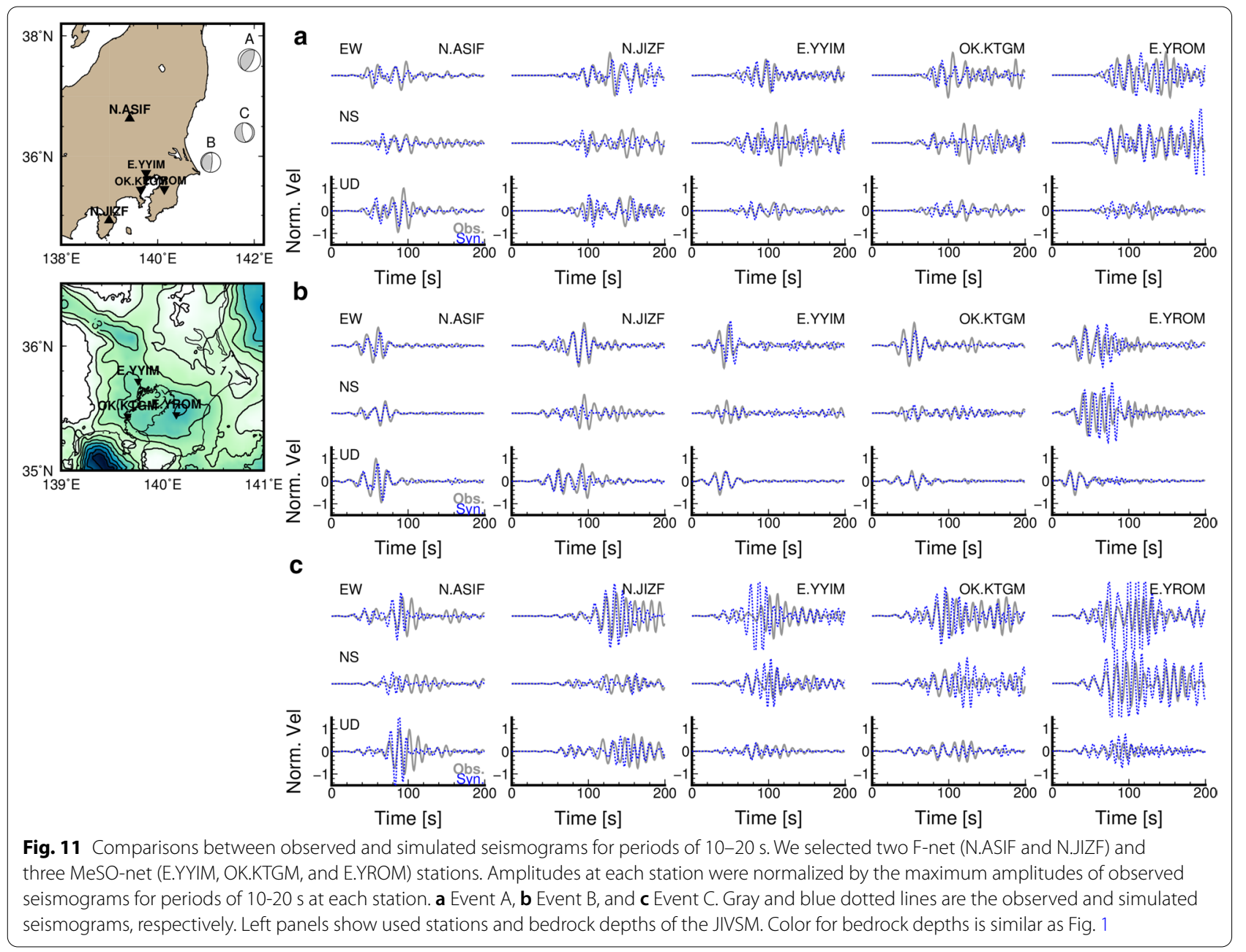

Simulations using the 3D CMT solutions in this study and the JIVSM were able to reproduce ground motion for periods longer than $5 \mathrm{~s}$ at outcrop rock sites. On the other hand, discrepancies between observations and simulations using F-net solutions could not be corrected by simple adjustment of seismic moments. These results mean that the 3D CMT inversion works well in the Kanto region, and 3D CMT solutions are suitable for modeling long-period (>5 s) ground motion. However, while simulations at stations within the Kanto Basin reproduced observed seismograms for periods longer than $10 \mathrm{~s}$, the reproducibility of these simulations decreased for periods shorter than $10 \mathrm{~s}$.
In the Kanto region, because the predominant period of long-period ground motion is approximately $6 \mathrm{~s}$, a wellconstrained sedimentary model is required to evaluate long-period ground motion for observed and anticipated large earthquakes. Recently, other regional/local velocity structure models of the sedimentary basin and subducting oceanic plate have been released (e.g., Hirose et al. 2008; Takemura et al. 2015; Headquarters for Earthquake Research Promotion 2017; Ito et al. 2019). The reproducibility of long-period ground motion in the Kanto Basin can be improved through the utilization of other published or adjusted models based on ground motion 


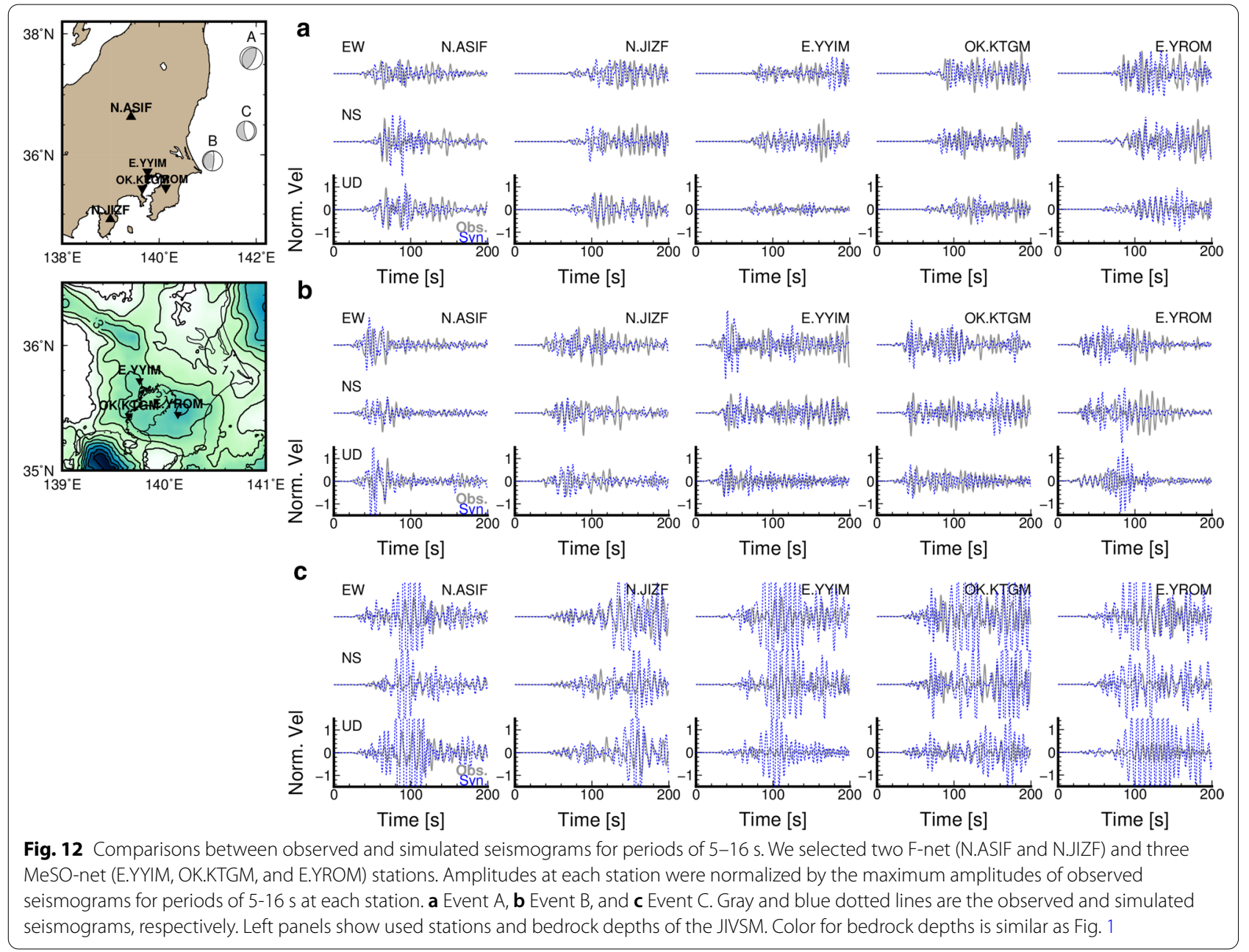

simulations using 3D CMT solutions; this should be the primary focus of future research.

\section{Supplementary information}

The online version contains supplementary material available at https://doi. org/10.1186/s40623-020-01348-2.

\section{Additional file 1: This additional file includes Figures S1-S7 and}

Table S1. Figure $\mathrm{S} 1$ shows CMT solutions at the optimal source grid as a function of centroid time. Figures S2 and S3 illustrate examples of CMT solutions of a shallow earthquake and broader period case. Figure $\$ 4$ shows comparisons of percentages of each component between our 3D and F-net catalogs. Simulated waveforms of Events A-C using F-net MT solutions are illustrated in Figure S5-S7. The list of used earthquakes in Figure $7 \mathrm{a}$ is in Tabel $\mathrm{S1}$.

\section{Abbreviations}

1D: One-dimensional; 3D: Three-dimensional; CMT: Centroid moment tensor; ERI-JURP: Earthquake Research Institute, the University of Tokyo Joint Usage/ Research Program; F-net: Full-range seismograph network; IIVSM: Japan Integrated Velocity Structure Model version 1; JST: Japan Standard Time; MeSO-net: Metropolitan Seismic Observation network; MT: Moment tensor; NIED: National Research Institute for Earth Science and Disaster Resilience;
OpenSWPC: Open-Source Seismic Wave Propagation Code; SAC: Seismic Analysis Code; SNR: Signal to noise; UTC: Coordinated Universal Time; VR: Variance Reduction.

\section{Acknowledgements}

Numerical simulations of seismic wave propagation were conducted using the computer system of Earthquake and Volcano Information Center at the Earthquake Research Institute, the University of Tokyo, and Fujitsu PRIMERGY CX600M1/CX1640M1 (Oakforest-PAC) at the Information Technology Center, the University of Tokyo. We thank Ryo Okuwaki for the useful discussions. We would like to thank Editage (www.editage.com) for English language editing

\section{Authors' contributions}

ST conducted a numerical simulation to synthesize Green's functions and long-period ground motion, CMT inversions of moderate size earthquakes in the Kanto region, and also drafted this manuscript. ST and KY investigated propagation features of long-period ground motions. ST and KS interpreted the local seismicity beneath the Kanto region. All authors read and approved the final manuscript.

\section{Funding}

This study was supported by the JSPS KAKENHI grant numbers 18K03786 in Grant-in-Aid for Scientific Research (C) and 19H04626 in Scientific Research on Innovative Areas "Science of slow earthquakes"This study was also supported by the ERI JURP 2020-S-04. 


\section{Availability of data and materials}

By using HinetPy (https://doi.org/10.5281/zenodo.3695076), NIED F-net and MeSO-net data were downloaded from https://hinetwww11.bosai.go.jp/ auth/? LANG=en. We used the open-source code OpenSWPC version 5.0.2 (https://doi.org/10.5281/zenodo.3712650) and the local 3D model "JIVSM" by Koketsu et al. (2012) from https://www.jishin.go.jp/evaluation/seismic_hazar d_map/lpshm/12_choshuki_dat/. Figure images were drawn using Generic Mapping Tools (Wessel et al. 2013) and the Seismic Analysis Code (Goldstein and Snoke 2005; Helffrich et al. 2013) was used in a part of signal processing works. The CMT solutions in Takemura et al. (2020) and this study are available from https://doi.org/10.5281/zenodo.3674161 and https://doi.org/10.5281/ zenodo.3926884, respectively. Simulation results for long-period ground motion are also available at https://doi.org/10.5281/zenodo.3926888.

\section{Ethics approval and consent to participate}

Not applicable.

\section{Consent for publication}

Not applicable.

\section{Competing interests}

The authors declare that they have no competing interests.

\section{Author details}

${ }^{1}$ Earthquake Research Institute, The University of Tokyo, 1-1-1 Yayoi, Bunkyo-ku, Tokyo 113-0032, Japan. ${ }^{2}$ Graduate School of Nanobioscience, Department of Material System Science, Yokohama City University, 22-2 Seto, Kanazawa-Ku, Yokohama, Kanagawa 236-0027, Japan. ${ }^{3}$ Earthquake and Tsunami Research Division, National Research Institute for Earth Science and Disaster Resilience, 3-1 Tennodai, Tsukuba, Ibaraki 305-0006, Japan.

Received: 14 July 2020 Accepted: 24 December 2020

Published online: 11 January 2021

\section{References}

Agata R (2020) Introduction of covariance components in slip inversion of geodetic data following a non-uniform spatial distribution and application to slip deficit rate estimation in the Nankai Trough subduction zone. Geophys J Int 221:1832-1844. https://doi.org/10.1093/gji/ ggaa116

Baba S, Takemura S, Obara K, Noda A (2020) Slow earthquakes illuminating interplate coupling heterogeneities in subduction zones. Geophys Res Lett. https://doi.org/10.1029/2020GL088089

Bernardi F, Braunmiller J, Kradolfer U, Giardini D (2004) Automatic regional moment tensor inversion in the European-Mediterranean region. Geophys J Int 157:703-716. https://doi.org/10.1111/j.1365-246X.2004.02215.x

Boore DM (1999) Basin Waves on a Seafloor Recording of the 1990 Upland, California, Earthquake: implications for Ground Motions from a Larger Earthquake. Bull Seismol Soc Am 89:317-324

Day SM, Graves R, Bielak J et al (2008) Model for Basin Effects on Long-Period Response Spectra in Southern California. Earthq Spectra 24:257-277. https://doi.org/10.1193/1.2857545

Ekström G, Nettles M, Dziewoński AM (2012) The global CMT project 20042010: centroid-moment tensors for 13,017 earthquakes. Phys Earth Planet Inter 200-201:1-9. https://doi.org/10.1016/j.pepi.2012.04.002

Fukuyama E, Ishida M, Dreger DS, Kawai H (1998) Automated seismic moment tensor determination by using on-line broadband seismic waveforms. Zisin 51:149-156. https://doi.org/10.4294/zisin1948.51.1_149

Furumura T, Hayakawa T (2007) Anomalous propagation of long-period ground motions recorded in Tokyo during the 23 October 2004 Mw 6.6 Niigata-ken Chuetsu, Japan, earthquake. Bull Seismol Soc Am 97:863880. https://doi.org/10.1785/0120060166

Furumura M, Furumura T, Wen KL (2001) Numerical simulation of Love wave generation in the llan Basin, Taiwan, during the 1999 Chi-Chi earthquake. Geophys Res Lett 28:3385-3388. https://doi.org/10.1029/2001GL013114

Furumura T, Hayakawa T, Nakamura M et al (2008) Development of longperiod ground motions from the Nankai trough, Japan, earthquakes: observations and computer simulation of the 1944 Tonankai (Mw 8.1) and the 2004 SE Off-Kii Peninsula (Mw 7.4) earthquakes. Pure Appl Geophys 165:585-607. https://doi.org/10.1007/s00024-008-0318-8

Gao H, Shen Y (2014) Upper mantle structure of the Cascades from full-wave ambient noise tomography: evidence for 3D mantle upwelling in the back-arc. Earth Planet Sci Lett 390:222-233. https://doi.org/10.1016/j. epsl.2014.01.012

Gokhberg A, Fichtner A (2016) Full-waveform inversion on heterogeneous HPC systems. Comput Geosci 89:260-268. https://doi.org/10.1016/j. cageo.2015.12.013

Goldstein P, Snoke A (2005) SAC Availability for the IRIS Community. In: Inc. Institutions Seismol. Data Manag. Cent. Electron. Newsl. https://ds.iris. edu/ds/newsletter/vol7/no1/193/sac-availability-for-the-iris-community/

Gomberg J (2018) Cascadia onshore-offshore site response, submarine sediment mobilization, and earthquake recurrence. J Geophys Res Solid Earth 123:1381-1404. https://doi.org/10.1002/2017JB014985

Guo Y, Koketsu K, Miyake H (2016) Propagation mechanism of long-period ground motions for offshore earthquakes along the nankai trough: effects of the accretionary wedge. Bull Seismol Soc Am 106:1176-1197. https://doi.org/10.1785/0120150315

Headquarters for Earthquake Research Promotion (2017) National seismic hazard maps for Japan. https://www.jishin.go.jp/evaluation/seismic_hazar d_map/shm_report/shm_report_2017/

Hejrani B, Tkalčić H (2020) Resolvability of the centroid-moment-tensors for shallow seismic sources and improvements from modelling high-frequency waveforms. J Geophys Res Solid Earth. https://doi. org/10.1029/2020JB019643

Hejrani B, Tkalčić H, Fichtner A (2017) Centroid moment tensor catalogue using a 3-D continental scale Earth model: application to earthquakes in Papua New Guinea and the Solomon Islands. J Geophys Res Solid Earth 122:5517-5543. https://doi.org/10.1002/2017JB014230

Helffrich GR (1997) How good are routinely determined focal mechanisms? Empirical statistics based on a comparison of Harvard, USGS and ERI moment tensors. Geophys J Int 131:741-750. https://doi.org/10.1111/ j.1365-246X.1997.tb06609.x

Helffrich G, Wookey J, Bastow I (2013) The Seismic Analysis Code. Cambridge University Press, Cambridge

Hirose F, Nakajima J, Hasegawa A (2008) Three-dimensional seismic velocity structure and configuration of the Philippine Sea slab in southwestern Japan estimated by double-difference tomography. J Geophys Res Solid Earth 113:1-26. https://doi.org/10.1029/2007JB005274

Ito A, Sugioka H, Obana K et al (2017a) Upper boundaries of the Pacific and Philippine Sea plates near the triple junction off the Boso Peninsula deduced from ocean-bottom seismic observations. Earth Planets Sp 69:30. https://doi.org/10.1186/s40623-017-0608-4

Ito A, Yamamoto Y, Hino R et al (2017b) Tomographic image of crust and upper mantle of the Boso Peninsula using data from an ocean-bottom seismograph array. Earth Planets Sp. https://doi.org/10.1186/s40623-017-0703-6

Ito A, Tonegawa T, Uchida N et al (2019) Configuration and structure of the Philippine Sea Plate off Boso, Japan: constraints on the shallow subduction kinematics, seismicity, and slow slip events. Earth Planets Sp 71:111. https://doi.org/10.1186/s40623-019-1090-y

Iwaki A, Maeda T, Morikawa N et al (2018) Effects of random 3D upper crustal heterogeneity on long-period ( $\geq 1 \mathrm{~s}$ ) ground-motion simulations. Earth Planets Sp 70:156. https://doi.org/10.1186/s40623-018-0930-5

Kanamori H, Brodsky EE (2004) The physics of earthquakes. Reports Prog Phys 67:1429-1496. https://doi.org/10.1088/0034-4885/67/8/R03

Kaneko Y, Ito Y, Chow B et al (2019) Ultra-long duration of seismic ground motion arising from a thick, low-velocity sedimentary wedge. J Geophys Res Solid Earth 124:10347-10359. https://doi.org/10.1029/2019JB017795

Kasahara K, Morita Y, Hirata N et al (2009) Development of the metropolitan seismic observation network (MeSO-net) for detection of mega-thrust beneath Tokyo metropolitan area. Bull Earthq Res Inst Univ Tokyo 2:71-88

Kennett BLN, Fichtner A, Fishwick S, Yoshizawa K (2013) Australian seismological referencemodel (AuSREM): mantle component. Geophys J Int 192:871-887. https://doi.org/10.1093/gji/ggs065

Kimura T, Murakami H, Matsumoto T (2015) Systematic monitoring of instrumentation health in high-density broadband seismic networks. Earth Planets Sp 67:55. https://doi.org/10.1186/s40623-015-0226-y

Kinoshita S, Fujiwara H, Mikoshiba T, Hoshino T (1992) Secondary Love waves observed by a strong-motion array in the Tokyo lowlands, Japan. J Phys Earth 40:99-116. https://doi.org/10.4294/jpe1952.40.99 
Koketsu K, Kikuchi M (2000) Propagation of seismic ground motion in the Kanto basin, Japan. Science (80-) 288:1237-1239. https://doi.org/10.1126/ science.288.5469.1237

Koketsu K, Miyake H (2008) A seismological overview of long-period ground motion. J Seismol 12:133-143. https://doi.org/10.1007/s1095 0-007-9080-0

Koketsu K, Miyake H, Afnimar Tanaka Y (2009) A proposal for a standard procedure of modeling 3-D velocity structures and its application to the Tokyo metropolitan area, Japan. Tectonophysics 472:290-300. https://doi. org/10.1016/j.tecto.2008.05.037

Koketsu K, Miyake H, Suzuki H (2012) Japan Integrated Velocity Structure Model Version 1. Proc 15th World Conf Earthq Eng 1-4

Komatitsch D (2004) Simulations of ground motion in the los angeles basin based upon the spectral-element method. Bull Seismol Soc Am 94:187-206. https://doi.org/10.1785/0120030077

Kubo A, Fukuyama E, Kawai H, Nonomura K (2002) NIED seismic moment tensor catalogue for regional earthquakes around Japan: quality test and application. Tectonophysics 356:23-48. https://doi.org/10.1016/S0040 $-1951(02) 00375-X$

Kuge K, Kawakatsu H (1993) Significance of non-double couple components of deep and intermediate-depth earthquakes: implications from moment tensor inversions of long-period seismic waves. Phys Earth Planet Inter 75:243-266. https://doi.org/10.1016/0031-9201(93)90004-S

Lee S-J, Liang WT, Cheng HW et al (2013) Towards real-time regional earthquake simulation I: real-time moment tensor monitoring (RMT) for regional events in Taiwan. Geophys J Int 196:432-446. https://doi. org/10.1093/gji/ggt371

Maeda T, Takemura S, Furumura T (2017) OpenSWPC: an open-source integrated parallel simulation code for modeling seismic wave propagation in 3D heterogeneous viscoelastic media. Earth Planets Sp 69:102. https:// doi.org/10.1186/s40623-017-0687-2

Matsubara M, Obara K (2011) The 2011 off the Pacific coast of Tohoku Earthquake related to a strong velocity gradient with the Pacific plate. Earth Planets Sp 63:663-667. https://doi.org/10.5047/eps.2011.05.018

Matsubara M, Obara K, Kasahara K (2008) Three-dimensional P- and S-wave velocity structures beneath the Japan Islands obtained by high-density seismic stations by seismic tomography. Tectonophysics 454:86-103. https://doi.org/10.1016/j.tecto.2008.04.016

Miyake H, Koketsu K (2005) Long-period ground motions from a large offshore earthquake: the case of the 2004 off the Kii peninsula earthquake, Japan. Earth Planets Sp 57:203-207. https://doi.org/10.1186/BF03351816

Miyazawa M (2016) An investigation into the remote triggering of the Oita earthquake by the $2016 \mathrm{Mw} 7.0$ Kumamoto earthquake using full wavefield simulation. Earth Planets Sp. https://doi.org/10.1186/s4062 3-016-0585-z

Miyoshi T, Obayashi M, Peter D et al (2017) Adjoint tomography of the crust and upper mantle structure beneath the Kanto region using broadband seismograms. Prog Earth Planet Sci 4:29. https://doi.org/10.1186/s4064 5-017-0143-8

Mukai Y, Furumura T, Maeda T (2018) Causes of azimuthally dependent amplification variations of long-period ground motions in the Kanto Basin, Central Japan. Bull Earthq Res Inst Univ Tokyo 93:31-48

Nakamura T, Takenaka H, Okamoto T et al (2015) Long-period ocean-bottom motions in the source areas of large subduction earthquakes. Sci Rep 5:1-2. https://doi.org/10.1038/srep16648

National Research Institute for Earth Science and Disaster Resilience (2019) NIED F-net. In: Natl. Res. Inst. Earth Sci. Disaster Resil. https://doi. org/10.17598/NIED.0005

Oba A, Furumura T, Maeda T (2020) Data Assimilation-Based Early Forecasting of Long-Period Ground Motions for Large Earthquakes Along the Nankai Trough. J Geophys Res Solid Earth. https://doi.org/10.1029/2019JB019047

Okada Y, Kasahara K, Hori S, et al (2004) Recent progress of seismic observation networks in Japan — Hi-net, F-net, K-NET and KiK-net—. Earth, Planets Sp 56:xv-xxviii. https://doi.org/10.1186/BF03353076

Okamoto T, Takenaka H, Nakamura T (2018) Evaluation of accuracy of synthetic waveforms for subduction-zone earthquakes by using a land-ocean unified 3D structure model. Earth Planets Sp. https://doi.org/10.1186/s4062 3-018-0871-z

Olsen KB, Day SM, Minster JB et al (2006) Strong shaking in Los Angeles expected from southern San Andreas earthquake. Geophys Res Lett 33:L07305. https://doi.org/10.1029/2005GL025472
Ryoki K (1999) Three-Dimensional Depth Structure of the Crust and Uppermost Mantle beneath Southwestern Japan and Its Regional Gravity Anomalies. Zisin (Journal Seismol Soc Japan 2nd ser) 52:51-63. https:// doi.org/10.4294/zisin1948.52.1_51

Sakai S, Hirata N (2009) Distribution of the Metropolitan Seismic Observation network. Bull Earthq Res Inst Tokyo Univ 84:57-69

Shinohara M, Hino R, Yoshizawa T et al (2005) Hypocenter distribution of plate boundary zone off Fukushima, Japan, derived from ocean bottom seismometer data. Earth, Planets Sp 57:93-105. https://doi.org/10.1186/ BF03352553

Stephenson WJ, Reitman NG, Angster SJ (2017) P- and S-wave velocity models incorporating the Cascadia subduction zone for 3D earthquake ground motion simulations, Version 1.6-Update for Open-File Report 2007-1348

Takemura S, Akatsu M, Masuda Ket al (2015) Long-period ground motions in a laterally inhomogeneous large sedimentary basin: observations and model simulations of long-period surface waves in the northern Kanto Basin, Japan. Earth Planets Sp 67:33. https://doi.org/10.1186/s40623-015-0201-7

Takemura S, Shiomi K, Kimura T, Saito T (2016) Systematic difference between first-motion and waveform-inversion solutions for shallow offshore earthquakes due to a low-angle dipping slab. Earth Planets Sp 68:149. https:// doi.org/10.1186/s40623-016-0527-9

Takemura S, Kimura T, Saito T et al (2018a) Moment tensor inversion of the 2016 southeast offshore Mie earthquake in the Tonankai region using a three-dimensional velocity structure model: effects of the accretionary prism and subducting oceanic plate. Earth Planets Sp 70:50. https://doi. org/10.1186/s40623-018-0819-3

Takemura S, Matsuzawa T, Kimura T et al (2018b) Centroid moment tensor inversion of shallow very low frequency earthquakes off the kii Peninsula, Japan, using a three-dimensional velocity structure model. Geophys Res Lett 45:6450-6458. https://doi.org/10.1029/2018GL078455

Takemura S, Kubo H, Tonegawa T et al (2019a) Modeling of Long-Period Ground Motions in the Nankai Subduction Zone: model Simulation Using the Accretionary Prism Derived from Oceanfloor Local S-Wave Velocity Structures. Pure Appl Geophys 176:627-647. https://doi.org/10.1007/ s00024-018-2013-8

Takemura S, Matsuzawa T, Noda A et al (2019b) Structural characteristics of the nankai trough shallow plate boundary inferred from shallow very low frequency earthquakes. Geophys Res Lett 46:4192-4201. https://doi. org/10.1029/2019GL082448

Takemura S, Shiomi K, Obara K (2019c) 3D simulation of seismic wave propagation during the MJMA 6.3 Hyuga-nada earthquake occurred on 10 May 2019. Rep Coord Comm Earthq Predict Japan 102:320-325

Takemura S, Okuwaki R, Kubota T et al (2020) Centroid moment tensor inversions of offshore earthquakes using a three-dimensional velocity structure model: slip distributions on the plate boundary along the Nankai Trough. Geophys J Int 222:1109-1125. https://doi.org/10.1093/gji/ggaa238

Tape C, Liu Q, Maggi A, Tromp J (2009) Adjoint tomography of the southern california crust. Science. 325:988-992. https://doi.org/10.1126/scien ce. 1175298

Vallée M, Charléty J, Ferreira AMG et al (2011) SCARDEC: a new technique for the rapid determination of seismic moment magnitude, focal mechanism and source time functions for large earthquakes using body-wave deconvolution. Geophys J Int 184:338-358. https://doi.org/10.1111/ j.1365-246X.2010.04836.x

Wang X, Zhan Z (2020) Moving from 1-D to 3-D velocity model: automated waveform-based earthquake moment tensor inversion in the Los Angeles region. Geophys J Int 220:218-234. https://doi.org/10.1093/gji/ggz435

Wessel P, Smith WHF, Scharroo R et al (2013) Generic mapping tools: improved version released. Eos 94:409-410. https://doi.org/10.1002/2013EO450001

Wirth EA, Vidale JE, Frankel AD et al (2019) Source-dependent amplification of earthquake ground motions in deep sedimentary basins. Geophys Res Lett 46:6443-6450. https://doi.org/10.1029/2019GL082474

Yoshimoto K, Takemura S (2014) A study on the predominant period of long-period ground motions in the Kanto Basin, Japan. Earth Planets Sp 66:100. https://doi.org/10.1186/1880-5981-66-100

\section{Publisher's Note}

Springer Nature remains neutral with regard to jurisdictional claims in published maps and institutional affiliations. 